\title{
Risky Business: Temporal and Spatial Variation in Preindustrial Dryland Agriculture
}

\author{
Charlotte T. Lee • Shripad Tuljapurkar • \\ Peter M. Vitousek
}

(C) Springer Science+Business Media, Inc. 2006

\begin{abstract}
Traditional dryland agriculture in the Pacific island was often labor-intensive and risky, yet settlement and farming in dry areas played an important role in the development of Polynesian societies. We investigate how temporal and spatial climatic fluctuations shape variation in agricultural production across dryland landscapes. We use a model that couples plant growth, climate, and soil organic matter dynamics, together with data from Kohala, Hawai'i, to understand how temperature, rainfall, nitrogen availability, and cropping activity interact to determine yield dynamics through time and space. Due to these interactions, the statistical characterization of rainfall alone is a poor characterization of agricultural yield. Using a simple linear model of human population dynamics, we show that the observed yield variation can affect long-term population growth substantially. Our approach to analyzing spatial and temporal fluctuations in food supply, and to interpreting the population consequences of these fluctuations, provides a quantitative evaluation of agricultural risk and human carrying capacity in dry regions.
\end{abstract}

Key words Spatiotemporal variation · dryland agriculture - agroecosystem dynamics · stochastic demography $\cdot$ Polynesia $\cdot$ Hawai'i.

\section{Introduction}

Distinct wet and dry areas occur on most Pacific high islands, and early Polynesians adapted their agricultural practices to island environments by developing distinctive wetland and dryland agricultural systems prior to European contact. Relative to irrigated cultivation in areas with permanent streams, dryland (rain-fed) agriculture was laborintensive, lower-yielding, and vulnerable to drought. Yet settlement in dry areas was often

C. T. Lee $(\bowtie) \cdot$ S. Tuljapurkar $\cdot$ P. M. Vitousek

Department of Biological Sciences, Stanford University, Stanford, CA 94305, USA

e-mail: charlotte.lee@stanford.edu

S. Tuljapurkar

e-mail: tulja@stanford.edu

P. Vitousek

e-mail: vitousek@stanford.edu 
widespread during the later periods of precontact history, and populations in these marginal areas frequently played a key role in the political dynamics of Polynesian chiefdoms (Kirch, 1994). Studies of dryland field systems have documented considerable heterogeneity in climate, topography, and soils that could have influenced variability in agricultural yield, and have suggested cultivation techniques and social strategies that might have evolved to increase or stabilize yields (Ladefoged and Graves, 2000, Allen, 2004, Kirch et al., in press). To better understand the long-term evolution of population and agriculture in dryland systems requires a quantitative understanding of how climatic and edaphic heterogeneities and human social choices interact to affect the dynamics of agroecosystems. This paper uses plant-soil models and a range of environmental data to examine the effect of temporal and spatial variability on agricultural productivity and risk in dryland agricultural systems. Our model provides a biologically based, temporally and spatially explicit analysis of the carrying capacity of these marginal agricultural systems.

Our analysis draws heavily on research in the Hawaiian Islands, but the methods and approach for linking physical and biological processes with human populations and society are more broadly applicable. Islands are useful model systems for understanding many aspects of ecology and culture: they are simpler than continents in important ways, and yet they are complex dynamic systems that embody essential features of continental systems (Vitousek, 2004). For understanding ecosystems, the relatively low species diversity, consistent geology, and wide and well-defined variation in climate and substrate age of the Hawaiian Islands allows us to evaluate biogeochemical processes with a precision that cannot be duplicated elsewhere (e.g., Chadwick et al., 1999, 2003). The archipelago also provided the context for the evolution of distinctive Hawaiian societies from an ancestral Polynesian group that, between initial colonization 600-900 A.D. and European contact in 1778-1789, achieved high population densities and remarkable economic specialization, social stratification, and religious sophistication (Kirch, 1985, Kirch et al., in press). The Islands are thus ideal for the study of the interplay between ecosystems and human population dynamics and culture, and we make use of this opportunity by drawing upon the wealth of archaeological, ecological, and biogeochemical work already conducted in Hawai'i to construct a model that shows how soil nutrient dynamics and plant growth act to translate temporal and spatial variation in climate into temporal and spatial variation in food supply.

Dryland agriculture in the Hawaiian archipelago took place primarily on geologically younger islands, especially Maui and Hawai'i (Vitousek et al., 2004). Correlations between climate and soil and the distribution of prehistoric agricultural activity have been evaluated on leeward volcanic slopes in North Kohala, Hawai'i, and Kahikinui, Maui (Kirch et al., 2004, Vitousek et al., 2004). These slopes experience steep rainfall gradients from dry conditions at sea level to annual precipitation of over $1.5 \mathrm{~m}$ per year at the higher elevations in Kahikinui and over $3 \mathrm{~m}$ per year in Kohala. Increasing rainfall weathers soil minerals from parent rock and mobilizes nutrients such as phosphorus $(\mathrm{P})$ and base cations more quickly, making them available for plant uptake in the short term, but also increasing the potential for leaching losses. The outcome is a steep decrease in soil fertility above a threshold amount of rainfall (Chadwick et al., 2003). This pattern of low nutrient availability at high elevations, together with arid conditions near the coast, implies that dryland ecosystem productivity should be highest at intermediate elevations. In Kohala and Kahikinui, concentrations of rock-derived nutrients do decline with elevation, and intermediate elevations show the most evidence of human cultivation (Kirch et al., 2004, Vitousek et al., 2004). These studies provide a powerful argument that climate and topography shape soil fertility on leeward volcanic slopes, defining dryland agricultural potential and constraining human settlement patterns. 
This paper complements these empirical studies with an analysis of temporal and spatial variability in plant production and agricultural yield as shaped by seasonal and stochastic variation in climate. We employ a coupled model of plants, nutrients, and soil organic matter based on the well-known CENTURY model (Parton et al., 1987), together with climate and other data from the Hawaiian dryland sites. This dynamical model enables us to examine month-to-month and year-to-year variation in plant productivity and agricultural yield, as well as variation in space across and along slopes. We find that the plant-soil system acts as a nonlinear filter of climate signals that amplifies climatic variability in some locations and suppresses it in others. Also, we use a simple model for human populations to show that the resulting variability in yield may be so substantial in some places as to reduce their agricultural value more than previously recognized.

We first describe the model and point out some of its key features. We then describe the topography and climate of the Kohala dryland field system, and outline our strategy for modeling agricultural yield and its population impacts across the landscape. Next, we begin with the important though unrealistic case of purely seasonal variation in rainfall and temperature, where climate fluctuates between months but follows the same monthly pattern in every year. We analyze the effects of seasonal climate at three different sites to show how temperature, moisture, nutrient supply, and annual harvesting determine the dynamics of sustainable plant production and of agricultural yield. We then add realistic stochastic variation in rainfall, and use long-term stochastic simulations to generate steadystate probability distributions of annual yield. This allows us to determine the probabilities of low and high yields at different locations, as well as to examine how the plant-soil system translates the rainfall distribution into the yield distribution at each site. In the following, we use a simple model of human population dynamics to explore the potential impact of observed food supply fluctuations, and then synthesize and extend these results to the entire dryland field system, showing how spatial variation in climatic drivers results in spatial variation in agricultural productivity and risk. We close with a discussion of the implications of our findings for preindustrial agriculturalists and of potential strategies for alleviating fluctuations in food supply.

\section{Ecosystem Model}

We base our analysis on the CENTURY model developed by Parton et al. (1987) which has been applied successfully to numerous and varied ecosystems (see, e.g., Bolker et al., 1998), including Hawaiian rainforests (Raich et al., 2000). The model achieves its impressive flexibility in part through a large number of functions that users customize with site-specific data. Unfortunately, these data rarely are available for studies of past ecosystem dynamics. Moreover, in this study we seek principles that are general to Pacific dryland agriculture, and our use of long-term simulation and detailed sensitivity analyses requires efficient computation. To achieve the necessary generality and simplicity, we use the core of the CENTURY model, shown in Fig. 1, and consider only carbon (C) and nitrogen (N). The dynamics of soil organic matter decay in a constant environment are represented as a system of difference equations of the form

$$
\begin{aligned}
& \boldsymbol{a}_{1}(t+1)=\mathbf{M}_{1} \boldsymbol{a}_{1}(t)+\boldsymbol{w}(t), \\
& \boldsymbol{a}_{2}(t+1)=\mathbf{M}_{2} \boldsymbol{a}_{2}(t)+\mathbf{K}_{1} \boldsymbol{a}_{1}(t), \\
& \boldsymbol{a}_{3}(t+1)=\mathbf{M}_{3} \boldsymbol{a}_{3}(t)+\mathbf{K}_{2} \boldsymbol{a}_{2}(t) .
\end{aligned}
$$




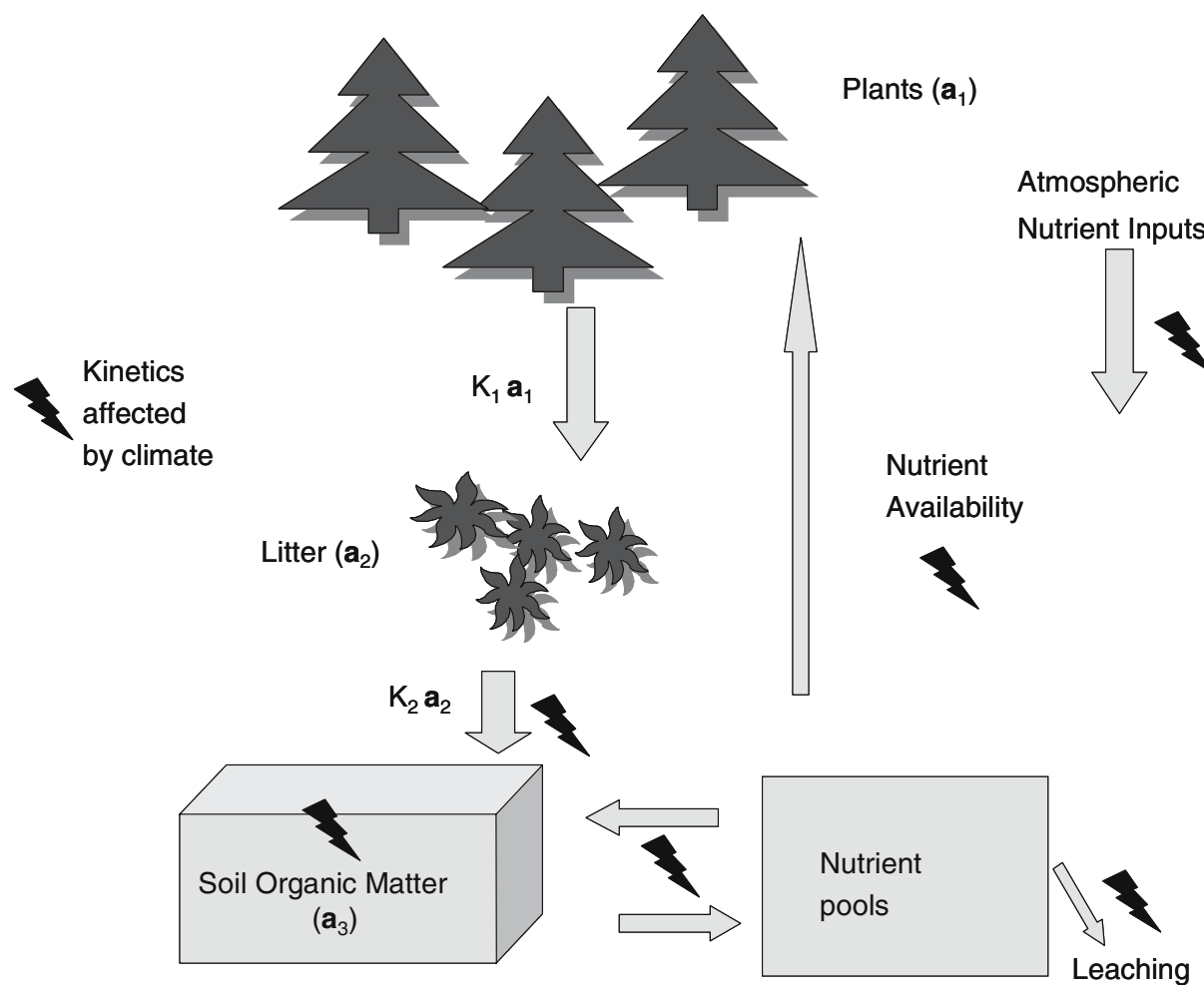

Fig. 1 Schematic representation of the core of the CENTURY ecosystem model.

Here the $\boldsymbol{a}_{i}(t)$ are vectors of $\mathrm{C}$ and $\mathrm{N}$ in compartment groups 1 (plants), 2 (litter), and 3 (soil organic matter). The vector $\boldsymbol{w}(t)$ represents inputs to plant compartments due to growth, specifically photosynthesis in the case of $\mathrm{C}$ and uptake from the soil for $\mathrm{N}$. The matrices $\mathbf{M}_{i}$ contain kinetic rates measuring transfers within each group of compartments, including material that remains in the same compartment. Finally the $\mathbf{K}_{i}$ are matrices of kinetic rates measuring transfers between groups of compartments, such as the death of plants and decay of litter. The kinetic constants that make up $\mathbf{M}_{i}$ and $\mathbf{K}_{i}$ for compartments 2 and 3 are functions of rainfall and temperature. The decomposition of litter and soil organic matter, together with leaching and additions from and losses to the atmosphere, determine the abundance of plant-available N. N, in turn, may influence plant growth, $\boldsymbol{w}(t)$, which is also a function of climate. The equations as summarized above suppress some of the model's complexity; we refer the reader to the literature for details (Comins and McMurtrie, 1993; Bolker et al., 1998; Baisden and Amundson, 2003). When climate varies through time, the $\mathbf{M}_{i}$ and $\mathbf{K}_{i}$ also vary through time.

We do not model $\mathrm{P}$ or other rock-derived plant nutrients explicitly. We analyze the model under the assumption that enough of these nutrients are present that they never limit plant growth or decomposition. As described above, however, we know that rock-derived nutrients decline at high levels of rainfall (Chadwick et al., 2003). Because P is not present in appreciable quantities in marine aerosols, $\mathrm{P}$ is the limiting nutrient at these higher rainfall levels (Chadwick et al., 1999, Vitousek, 2004). We discuss below the qualitative effects on our results of P limitation at higher rainfall. Parton et al. (2005) recently developed a means 
of incorporating changing long-term $\mathrm{P}$ inputs into CENTURY that may allow us to add $\mathrm{P}$ to our model in the future.

To implement the model, we use the $\mathbf{M}_{i}, \mathbf{K}_{i}$, and other functions developed for CENTURY in Parton et al. (1987), and use a monthly time step. To capture important features of island dryland agricultural systems, however, we have modified their model in several ways. First, the hydrological properties of volcanic soils are quite different from those for which CENTURY was developed. To determine nutrient leaching, we use models of water flow and soil water-holding capacity based on Chadwick et al. (2003); these indicate that for our purposes, soil water-holding capacity (our proxy for soil texture) is similar across the Kohala field system. Second, following CENTURY version 4.5 (Metherell et al., 1993), we calculate potential evapotranspiration (PET) at different elevations using Linacre's (1977) formula for green vegetation. Finally, we include an 'immobilization shutdown' as in recent versions of CENTURY (W. Parton, personal communication) to slow down the decay of organic material when there is insufficient nitrogen available for microbes to break down this substrate. We obtain parameters for $\mathrm{N}$ inputs and losses by matching the model to observed patterns in Kohala. With plant parameters appropriate for grass, which currently covers the leeward slope, we run the model with $\mathrm{N}$ fixation levels of $0.1 \mathrm{~g} / \mathrm{m}^{2} /$ year and atmospheric inputs of $\mathrm{N}$ that are based on those in Vitousek (2004), but depend linearly on rainfall. We tune losses of $\mathrm{N}$ due to leaching and to volatilization to obtain $\mathrm{N}$ mineralization rates that are reasonable for the substrate age and current observed range of rainfall in Kohala. Finally, we parameterize the model for sweet potato, Ipomoea batatas, the primary crop grown in dryland Hawai'i (Yen, 1974). The values we use for model parameters are given in Table I.

\section{The Kohala Field System: Modeling Approach}

The Kohala field system, which covers about $60 \mathrm{~km}^{2}$ on the leeward slopes of Kohala Mountain, Hawai'i Island, is characterized by a dense grid of stone-and-earthern field walls and paved trails (see, e.g., Ladefoged et al., 2003). The shaded area in Fig. 2 shows the boundaries of archeological evidence of the dryland field system, together with annual rainfall isohyets from the State of Hawai'i database and elevation contours. Elevation increases from west to east on the leeward western portion of the peninsula, and the northern areas are lower in overall elevation than southern ones. Higher elevations are cooler and receive more rain on average than lower ones, and the rainfall at lower elevations is more variable through time because lower elevations receive a higher percentage of their moisture from occasional winter storms (Giambelluca and Schroeder, 1998). In addition, more northerly locations in Kohala receive more rain at a given elevation than do southern ones, as northern areas are less sheltered from northeast trade winds. The topography of the peninsula thus results in a complex relationship between elevation and rainfall across the leeward slope.

To apply our model to this landscape, we treat each modeled location independently, using the temperature and rainfall dynamics at a given site to generate soil organic matter dynamics and plant growth through time at that site. Following the original CENTURY model, each location is treated as being $1 \mathrm{~m}^{2}$ in spatial extent and $20 \mathrm{~cm}$ in depth. We report modeled plant production and agricultural yield in units of tons per hectare, although the topography of an area may cause plant production to vary substantially within a given hectare. We examine three sites in detail: the first is within the rainfall range of the field system but falls on its upper elevational boundary, the second is within the elevational 
Table I Model Parameters

\begin{tabular}{|c|c|c|c|}
\hline & Parameter & Value & Source \\
\hline \multirow[t]{12}{*}{$\begin{array}{l}\text { Sweet potato } \\
\text { parameters }\end{array}$} & Root:shoot ratio & $3: 1$ & $\begin{array}{l}\text { (W. Parton, personal } \\
\text { communication) }\end{array}$ \\
\hline & Maximum $\mathrm{C}: \mathrm{N}$ ratio & 175 & Woolfe, 1992 \\
\hline & Minimum $\mathrm{C}: \mathrm{N}$ ratio & 55 & Woolfe, 1992 \\
\hline & Lignin content, root & $6 \%$ & $\begin{array}{l}\text { (W. Parton, personal } \\
\text { communication) }\end{array}$ \\
\hline & Lignin content, shoot & $15 \%$ & $\begin{array}{l}\text { (W. Parton, personal } \\
\text { communication) }\end{array}$ \\
\hline & Dry mass, root & $30 \%$ & Woolfe, 1992 \\
\hline & Dry mass, shoot & $13 \%$ & Woolfe, 1992 \\
\hline & Shoot death rate & $6 \% /$ month & (Parton et al., 1987) \\
\hline & Root death rate & $4 \% /$ month & (Parton et al., 1987) \\
\hline & Optimal rainfall & $75-100 \mathrm{~cm} /$ year & Onwueme, 1978 \\
\hline & Optimal temperature & $26^{\circ} \mathrm{C}$ & Purseglove, 1968, Woolfe, 1992 \\
\hline & Maximum possible production & 10 tons $/$ ha/month & (Burtenshaw et al., 2003) \\
\hline \multirow[t]{5}{*}{$\begin{array}{l}\text { Site } \\
\text { parameters }\end{array}$} & Soil pore volume, top $20 \mathrm{~cm}$ & $6.75 \mathrm{~cm}$ & $\begin{array}{l}\text { (O. Chadwick, personal } \\
\text { communication) }\end{array}$ \\
\hline & $\mathrm{N}$ leaching rate & $0.03 \mathrm{~g}$ per $\mathrm{m}^{2}$ per $\mathrm{V} / \mathrm{V} 0$ & \\
\hline & $\mathrm{N}$ fixation rate & $0.0083 \mathrm{~g} / \mathrm{m}^{2} / \mathrm{month}$ & (Vitousek, 2004) \\
\hline & $\mathrm{N}$ addition rate & $\begin{array}{l}0.0024 \mathrm{~g} / \mathrm{m}^{2} / \\
(\mathrm{cm} \text { rainfall })\end{array}$ & \\
\hline & $\begin{array}{l}\mathrm{N} \text { volatilization rate (percentage } \\
\text { of gross mineralization) }\end{array}$ & $\begin{array}{l}\operatorname{Max}(0,0.0322-0.0018 / \\
(\mathrm{cm} \text { rainfall }))\end{array}$ & \\
\hline
\end{tabular}

Parentheses around sources indicate that the value of the corresponding parameter is not explicitly given, but is calculated from information in the source.

range but is drier than any point in the field system, and the third is representative of cultivated sites in terms of both rainfall and elevation. These three locations exemplify the combinations of climate variables that occur in leeward Kohala, and our analysis of their dynamics illustrates the ways in which climate can influence the temporal pattern of plant production and agricultural yield. With yield distributions in hand, we use simple assumptions about how population birth and death rates depend on yield to translate food supply at each site into potential growth rates for localized human populations. To understand the spatiotemporal variation in food supply across whole leeward agricultural regions, we then examine the rainfall and yield dynamics at ten points along four elevational transects across the field system (Fig. 2). We analyze yields at each site and also average along the transects to investigate the effects of sharing within traditional Hawaiian social units.

To generate rainfall series for any point within the field system, we use 60 -year empirical records of monthly rainfall from three reference sites with rainfall levels that span the range of the field system (Fig. 3). The records are provided by Kahua Ranch, which monitors the sites as cooperative weather stations for the National Climatic Data Center. The three reference sites lie along an approximate elevational gradient, so we take them to be representative of the relationship between average rainfall and temporal variability in rainfall across the field system. For each of ten points along each transect, we weight the observed rainfall series from the two most similar reference sites by their differences from that point in average rainfall relative to the total difference between that point and the two 


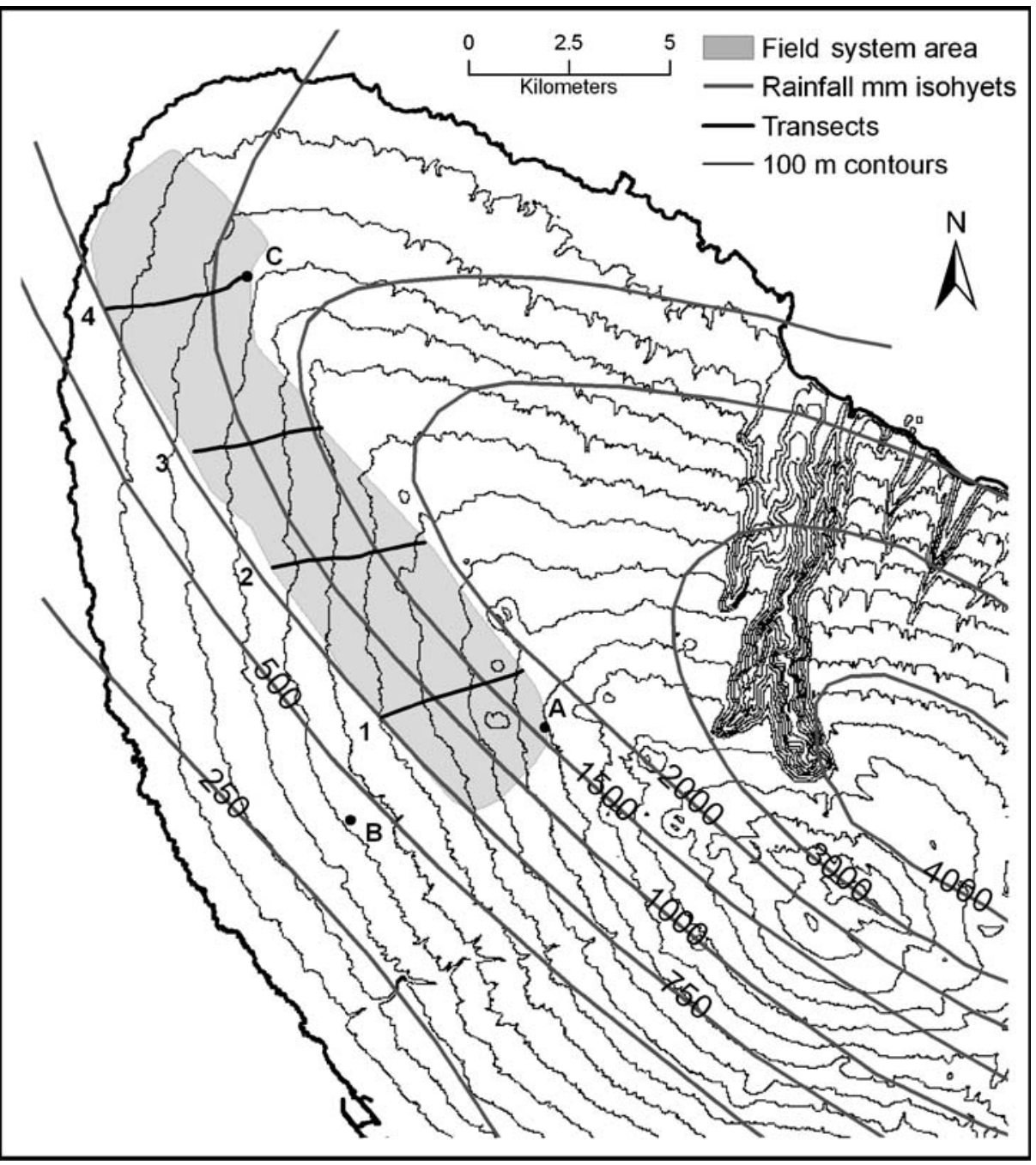

Fig. 2 Map of the Kohala peninsula showing the dryland field system (shaded area), elevation contours (thin grey lines), and annual rainfall isohyets (thick grey lines), courtesy of T. Ladefoged (2005). Isohyets are taken from the State of Hawai'i database. Climate and agricultural yield are modeled at Sites A, B, and C and along elevational Transects 1 through 4.

reference sites. Adding the two weighted series produces a rainfall series at each point that preserves the correlation structure of observed rainfall at two reference sites. Figure 3 shows the elevation and resulting simulated average rainfall along these four field system transects, and for the three reference sites. This figure is in reasonable agreement with Fig. 2, lending support to our climate modeling approach. Differences between rainfall statistics that we report for reference sites (e.g., Fig. 3) and the isohyets shown in Fig. 2 are due to the methods used to generate published island-wide rainfall contours $(\mathrm{O}$. Chadwick, personal communication), and we rely upon locally collected data in cases of discrepancy. 


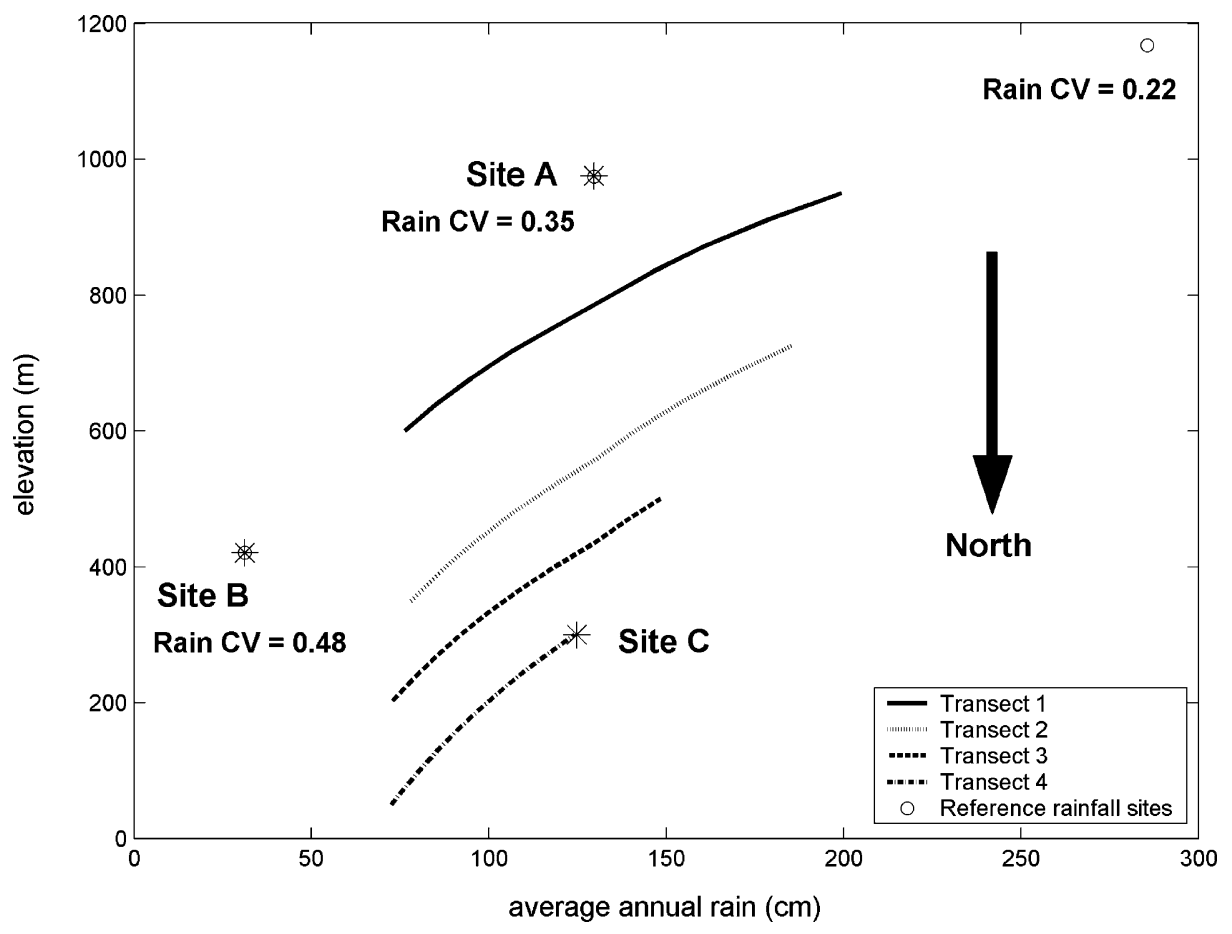

Fig. 3 Relationship between average rainfall and elevation along each field system transect and at Sites A, B, and $\mathrm{C}$ (asterisks). The three reference sites that provide rainfall data are shown with open circles. These sites have been monitored by Kahua Ranch as cooperative weather stations for the National Climatic Data Center. Sites $\mathrm{A}$ and $\mathrm{B}$ are also reference rainfall sites.

\section{Temporal Variation that Varies Through Space: A Tale of Three Sites}

\section{Purely Seasonal Climatic Variation}

We first examine how the model responds to seasonal variation in climate. Though unrealistic, the case of within-year variation that is constant between years forms the groundwork for our later analysis of rainfall that varies randomly as well as seasonally within and between years. For a given site, we average the rain for each of the months in the year to obtain a repeating 12-month series that captures observed seasonal variation. Temperatures at sites for which we have data are described well by a sinusoid, with seasonal variation in amplitude of $10 \%$ around the mean, and with a maximum in August and a minimum in February. We calculate the average temperature for each site as a function of elevation using a lapse rate for Hawai'i (Giambelluca and Schroeder, 1998). We now examine in detail three sites whose dynamics illustrate the range of behaviors that occur within the peninsula, first investigating the uncropped agricultural system before adding the effects of harvesting. Two of these sites are also reference rainfall sites, but the third is not (Fig. 3).

Under stable seasonal patterns of climate, the model eventually settles into a stable seasonal pattern where the dynamics of plant production are the same from year to year, although within-year variation may be substantial. Site A, at an elevation of $975 \mathrm{~m}$, has an 
average temperature of $17.7^{\circ} \mathrm{C}$ (Fig. 4a) and average monthly rainfall of $10.8 \mathrm{~cm}$ (Fig. $4 \mathrm{~b}$ ). This site is at the upper elevational boundary of the southern portion of the field system, and is perhaps the highest cultivated location on the peninsula (Fig. 2). The amount of rainfall it receives is representative of much of the field system (Fig. 3). We can determine the direct effects of climate on plant production by calculating the amount of plant production that rainfall and temperature would allow if $\mathrm{N}$ were available in excess (Fig. 4c, solid line). Comparison of this stable seasonal pattern of potential sweet potato production with temperature and rainfall patterns shows that potential production responds to temperature in the cooler, wetter season, but not to month-to-month variation in rainfall. In contrast, during the warmer, drier season, small changes in water availability result in large responses in potential production. Realized sweet potato production in this uncropped system (Fig. 4c, dotted line) is almost always identical to potential production, showing that $\mathrm{N}$ is usually abundant at this site relative to the growth allowed by rainfall and temperature. The overall result is that the plant-soil system amplifies rainfall fluctuations in the drier months but suppresses them in the wetter ones. We sum monthly plant production from November through October to obtain an annual production without cropping of 7.01 tons/ ha at Site A.

Site $\mathrm{B}$, at $421 \mathrm{~m}$ elevation, has a mean temperature of $21.3^{\circ} \mathrm{C}$ and mean monthly rainfall of $2.6 \mathrm{~cm}$ (Fig. 5a). This site lies within the elevational range of the field system but receives less precipitation than cultivated sites (Figs. 2 and 3). Here, in contrast to the higher-elevation Site A, the steady monthly pattern of realized sweet potato production (Fig. 5c, dotted line) does not track either temperature or rain. In addition, the monthly pattern of potential production (Fig. 5c, solid line) is very different from realized prod-

a.

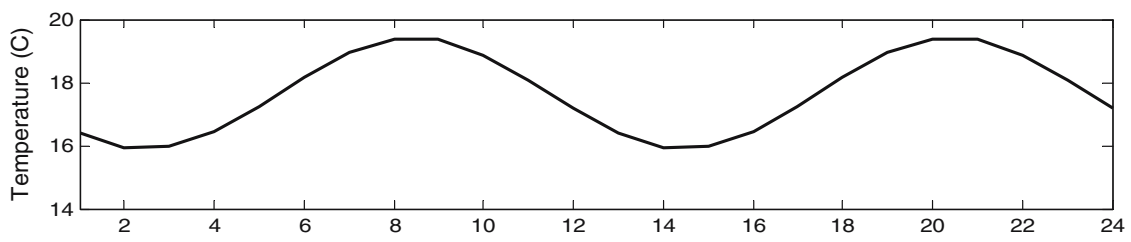

b.
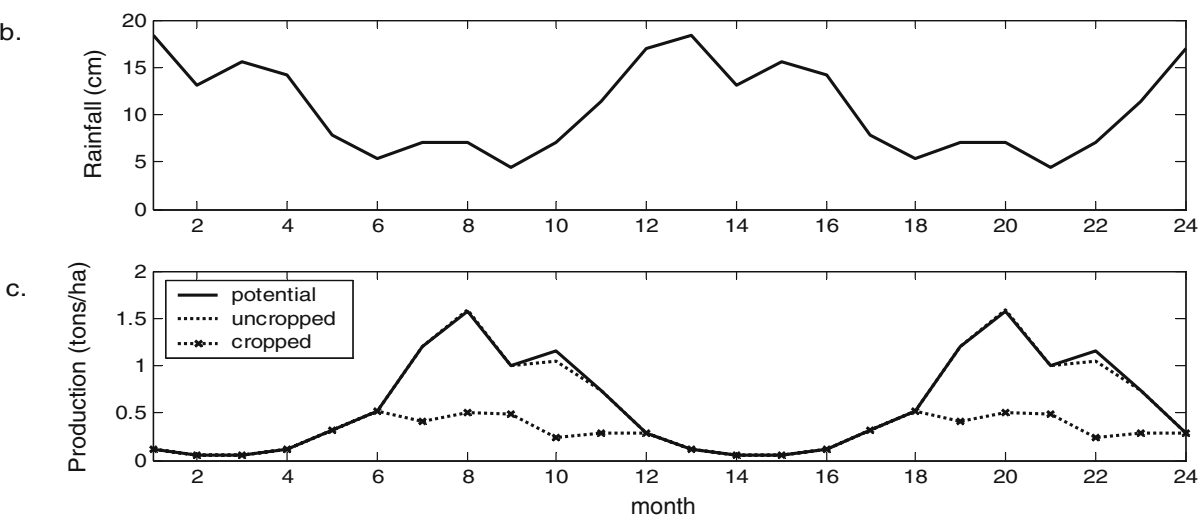

Fig. 4 Climate and plant production dynamics at Site A under purely seasonal climatic variation. a Seasonal temperature variation repeats indefinitely (two years shown). b Two years of seasonal rainfall variation. c Potential plant growth (solid line) is a function of temperature and effective rainfall. Realized production without cropping (dotted line) and with cropping (dotted line with symbols). 
a.

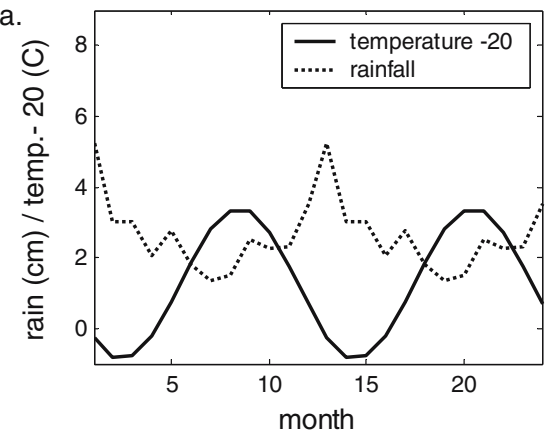

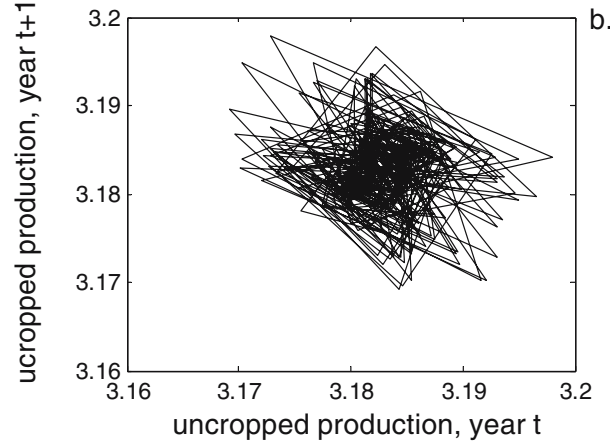

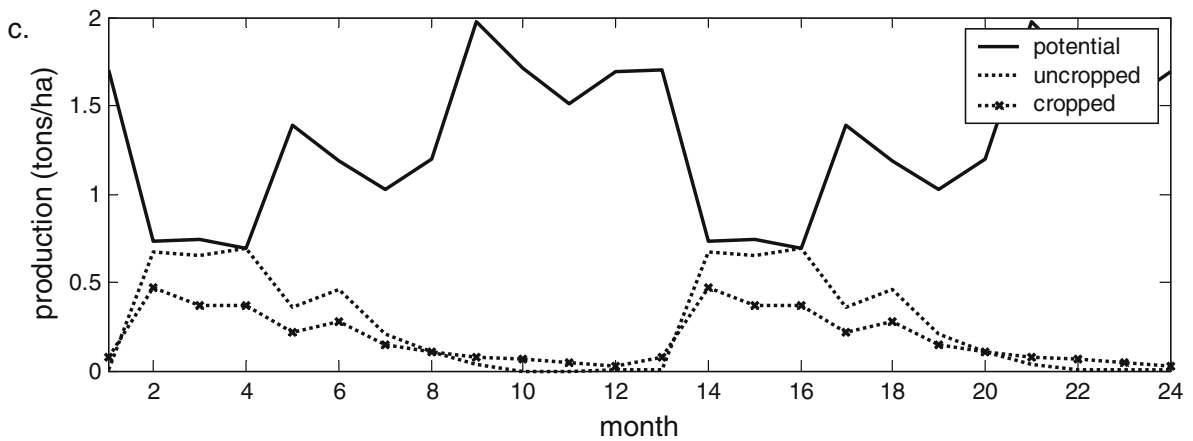

Fig. 5 Climate and production dynamics at Site B with purely seasonal climatic variation. a Two years of temperature (solid line) and rainfall (dotted line). The solid line shows temperature minus $20^{\circ} \mathrm{C}$ to facilitate display. b Plant production in the uncropped system varies from year to year even though climate does not. c Potential production (solid line), realized production without cropping (dotted line), and with cropping (dotted line with symbols).

uction. The reason for this difference is that at this site climate interacts with $\mathrm{N}$ availability in two important ways.

First, $\mathrm{N}$ inputs and losses depend on rain: atmospheric inputs of $\mathrm{N}$ are lower with lower rainfall, total gaseous losses are higher, and leaching losses are lower. The net result is generally lower $\mathrm{N}$ levels in drier areas. Second, seasonal climatic variation causes competition for $\mathrm{N}$ between microbes and plants at Site B. Climatic conditions that favor potential sweet potato growth also generally favor potential organic matter decomposition. In most systems, decomposition results in net microbial release of organic $\mathrm{N}$ to plantavailable forms, so that favorable climates increase both potential and realized plant production (Burke et al., 1997). Below ground sweet potato tissue, however, is starchy and therefore has a high $\mathrm{C}: \mathrm{N}$ ratio. Microbes require $\mathrm{N}$ to decompose this tissue, which makes up $75 \%$ of the total dry weight of the plant, so that climatic conditions that encourage decomposition can result in increased microbial demand for $\mathrm{N}$ and reduced $\mathrm{N}$ availability for plants. The production dynamics at Site B reflect this process. As the warm season proceeds, potential plant production increases (Fig. 5c, solid line), but the $\mathrm{N}$ available for plant growth decreases because microbes are incorporating it into soil organic matter. Realized production declines as a result (Fig. 5c, dotted line). When the site cools, less litter decomposition takes place, reducing microbial $\mathrm{N}$ demand and allowing plants to acquire some $\mathrm{N}$ for growth. Realized production increases even though potential production is lower in the cooler months. Thus, seasonal climatic forcing, together with a general 
shortage of $\mathrm{N}$ and high $\mathrm{C}: \mathrm{N}$ plant tissue, results in low realized plant production at times when potential production is highest. The high water-holding capacity of volcanic soils contributes to this effect by reducing microbial $\mathrm{C}$ respiration, as fine texture does in nonvolcanic soils (Parton et al., 1987, Burke et al., 1997).

The competition between microbes and plants for mineral $\mathrm{N}$ at Site B is so intense that decomposition in the model becomes a nonlinear process, as microbes cannot completely consume starchy plant material if not enough $\mathrm{N}$ is available. Monthly decomposition rates thus become dependent not only on temperature and soil moisture, as indicated in the model section, but also on available $\mathrm{N}$, which itself depends on decomposition rates as well as inputs and losses. The most striking consequence of this nonlinearity is variation in year-toyear sweet potato production at Site B, despite the fact that there is no year-to-year variation in the driving climate variables. Figure $5 \mathrm{~b}$ shows 1,000 years of annual realized production at Site B plotted against the previous year's realized production, and reveals slight, unpredictable year-to-year variation around a mean of 3.185 tons/ha. A similar plot for Site A shows convergence to a single point, implying that annual production is the same from year to year when decomposition dynamics are linear. We show below that these nonlinearities in decomposition and the variation in realized production that they cause, both revealed by our analysis of seasonal climatic variation, play an important role in the dynamics of stochastically varying systems.

Site $\mathrm{C}$ is located on the upper boundary of the northern part of the field system, at approximately $300 \mathrm{~m}$ elevation (Fig. 2). Its lower elevation results in higher temperatures than at Sites $\mathrm{A}$ or $\mathrm{B}$, with an average of $22.0^{\circ} \mathrm{C}$. Average monthly rainfall at the site is $10.4 \mathrm{~cm}$, almost the same amount of rainfall as Site A. Unlike the previous two locations, Site $\mathrm{C}$ thus experiences rainfall and temperature that are both representative of the field system (Fig. 3). Figure 6 shows the climate variables, potential production, and realized production at this site. The seasonal pattern of rainfall variation is almost identical to that at Site A, but because of higher temperatures, the patterns of potential and realized production are completely different. Higher evapotranspiration due to greater warmth at Site $\mathrm{C}$ reduces water availability in comparison with Site A, but it does not offset increases in both potential plant growth and potential decomposition that are also due to warmer temperatures. The net result is that competition between microbes and plants for $\mathrm{N}$ is more intense than at Site A, giving rise to dynamics like those at Site B even though rainfall and total N are more abundant at Site C. Realized production (Fig. 6c, dotted line) is nitrogen limited in all months relative to potential production (Fig. 6c, solid line), though realized production is generally much higher than at the other two sites. As at Site B, realized production is higher when potential growth is lower and varies slightly between years (mean annual production = 12.57 tons/ha; standard deviation $=0.0019$ tons/ha). Thus, the production dynamics at Site $\mathrm{C}$ demonstrate that nonlinearities in decomposition and their associated variability can occur for a range of combinations of rainfall and temperature across the Kohala peninsula, including climates that are much more favorable to plant growth than conditions at Site B.

The analysis of uncropped systems may not accurately depict the agricultural potential of a given site, because harvest removals of plant biomass can alter the dynamics of a system by changing the amounts of carbon and nitrogen cycling through it. We introduce cropping into the model by removing $85 \%$ of below ground biomass from the system once per year, at the beginning of November (changing the timing of the annual harvest alters the quantitative results reported here only slightly). We examine the sustainable annual yield, which is the sweet potato mass per unit area collected each November from the three sites after each achieves its stable seasonal pattern. Yield is always less than annual realized production when the cropped system is stable in the long term, because annual inputs to 

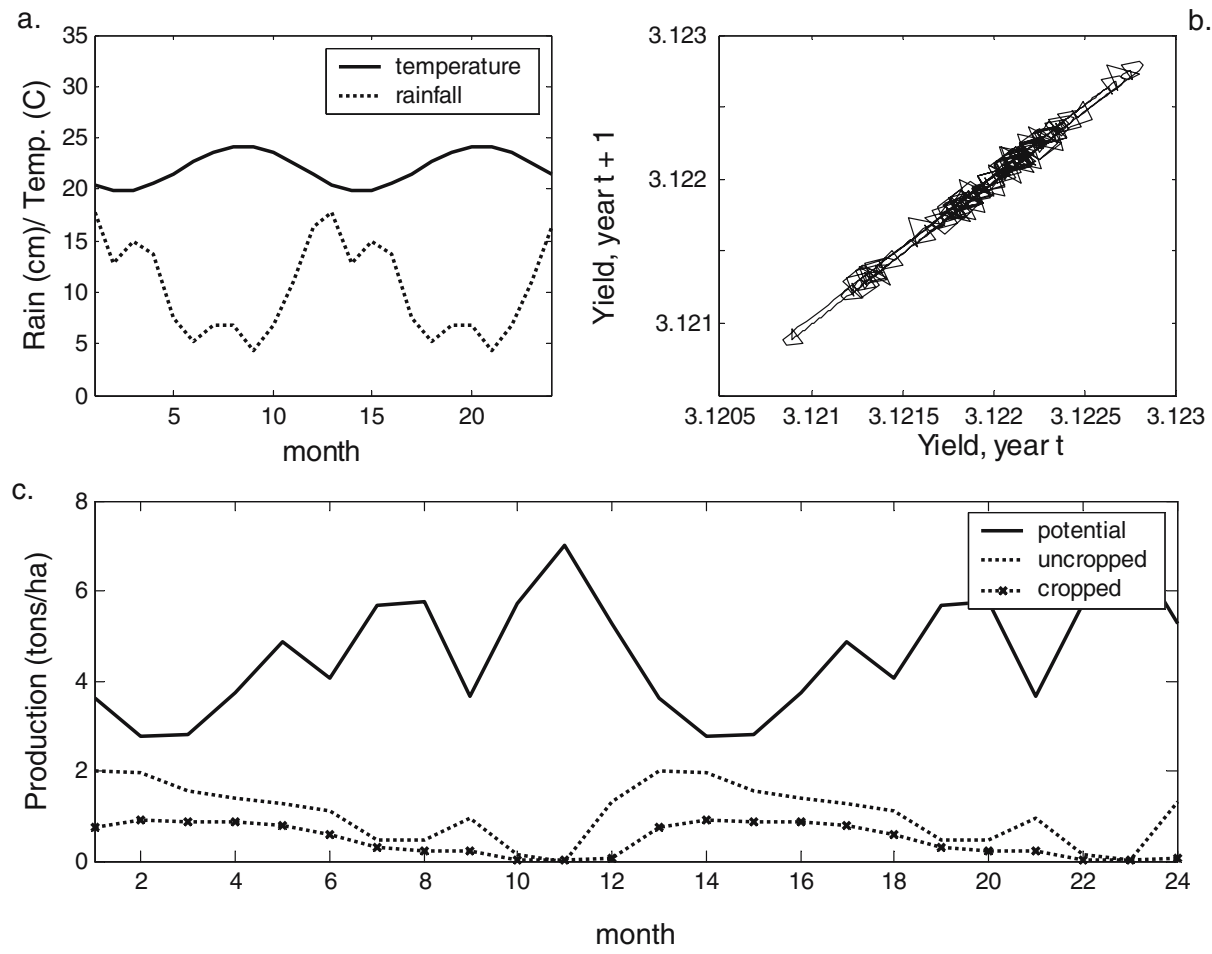

Fig. 6 Climate and production dynamics at Site $\mathrm{C}$ with purely seasonal climatic variation. a Two years of temperature (solid line) and rainfall (dotted line). b Agricultural yield varies from year to year. Cropping does not eliminate variation as at Site B. c Potential production (solid line), realized production without cropping (dotted line), and with cropping (dotted line with symbols).

below ground tissue via growth are equal to losses due to natural root death as well as harvest removals. At Site A, realized production in the cropped system remains temperature-limited in the cool months, but becomes N-limited in the warm ones because of harvest removals of $\mathrm{N}$ (Fig. 4c, dotted line with symbols). The resulting annual realized production is 3.39 tons/ha, as opposed to 7.01 tons/ha when uncropped; annual yield is 2.01 tons/ha. At Site B, cropping increases $\mathrm{N}$ limitation of realized production relative to the uncropped system (Fig. 5c, dotted line with symbols). Annual realized sweet potato growth is depressed from 3.19 to 2.22 tons/ha, with a yield of 1.24 tons/ha. This depression of realized plant production, together with removal of much of the plant's starchy tissue, eliminates nonlinearities: in the cropped system, neither annual realized production nor yield shows any year-to-year variation, and slightly more realized production occurs at the end of the dry season than in the uncropped system due to relief of microbial $\mathrm{N}$ demand (Fig. 5c). At Site $\mathrm{C}$, however, cropping only partly mitigates $\mathrm{N}$ competition between microbes and plants. Cropping increases $\mathrm{N}$ limitation to realized production at this site as well (Fig. 6c, dotted line with symbols) and decreases annual realized plant production from 12.57 tons/ha to 5.67 tons/ha, but Fig. 6b shows that annual yield varies slightly nonetheless. This demonstrates that nonlinear dynamics arising from $\mathrm{N}$ limitation to decomposition are more pronounced at Site $\mathrm{C}$ than at Site B, where no variation is observed in the cropped system. Annual yield at Site $\mathrm{C}$ is 3.12 tons/ha, with a standard deviation of 0.0014 tons/ha. 
We have shown how distinct seasonal rainfall and temperature combinations at different locations produce distinct dynamics in realized production and in yield. We now examine the effects of realistic stochastic variation in rainfall on agricultural yields. Though Hawaiian dryland field systems were occupied for a few hundred years at most, useful statistical characterization of randomly varying systems requires analysis over long periods of time to allow the dynamics to settle into a statistically stable state and to capture the effects of infrequent events. To obtain long monthly rainfall series that reflect observed patterns of variation, we repeatedly sample the reference precipitation series in random 25year segments, wrapping the sample to the beginning of the sequence when necessary, before using them to simulate rainfall elsewhere in the system.

Figure 7 (top panel) shows histograms of 2,000 years of simulated annual rainfall at the three sites. Site B is the driest and has the least rainfall variability in absolute terms (mean $+/-$ standard deviation $=31.8+/-15.3 \mathrm{~cm})$, but variation as a proportion of the mean is highest $(\mathrm{CV}=$ standard deviation $/$ mean $=0.48)$. As elevation increases to Site A, average annual rainfall and absolute variability increase to $127.9+/-44.7 \mathrm{~cm}$, while variation relative to the mean decreases $(\mathrm{CV}=0.35)$. Rainfall at Site $\mathrm{C}$ is very similar to Site A. Differences in the shapes of the distributions as well as in their means and standard deviations reveal that the patterns of variation are different from site to site. Figure 8 (top panel) shows empirical
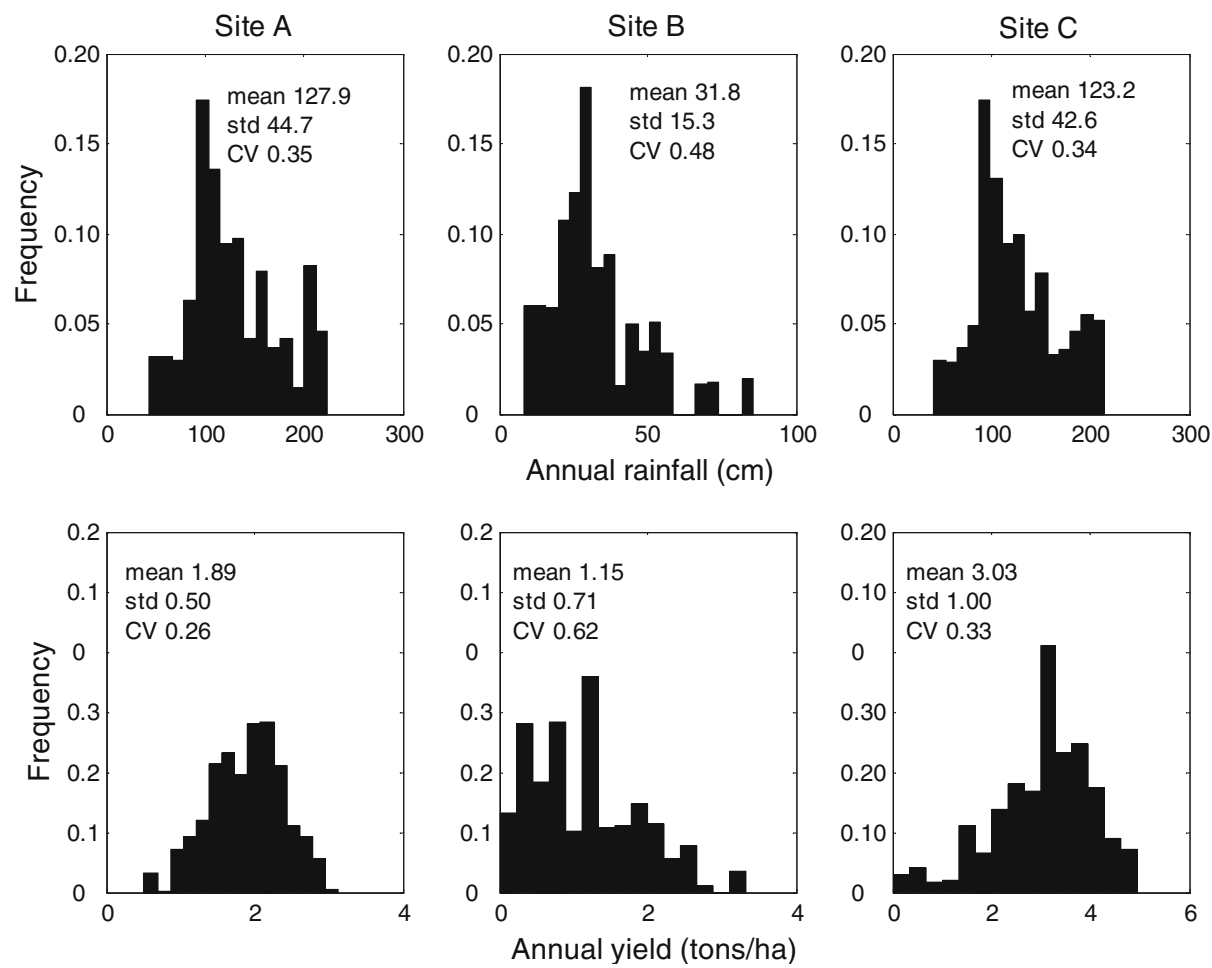

Fig. 7 Histograms of annual rainfall (top row) and annual yield (bottom row) for Sites A, B, and C. $X$-axes show values of annual yield (tons/ha) or annual rainfall $(\mathrm{cm}) ; y$-axes show the frequency with which values are observed in 2,000 years. Note changes in $y$-axes between rows and $x$-axes between columns. 
a.

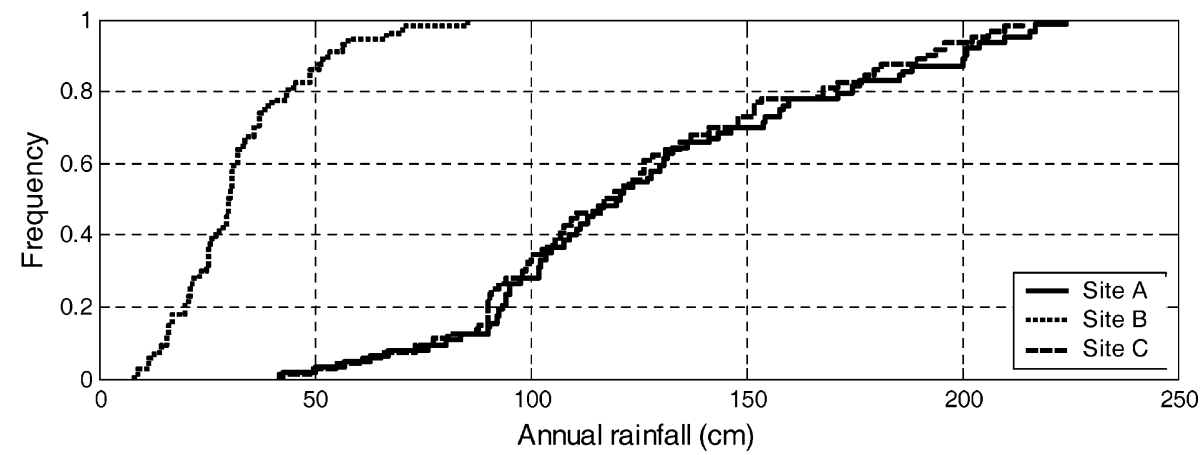

b.

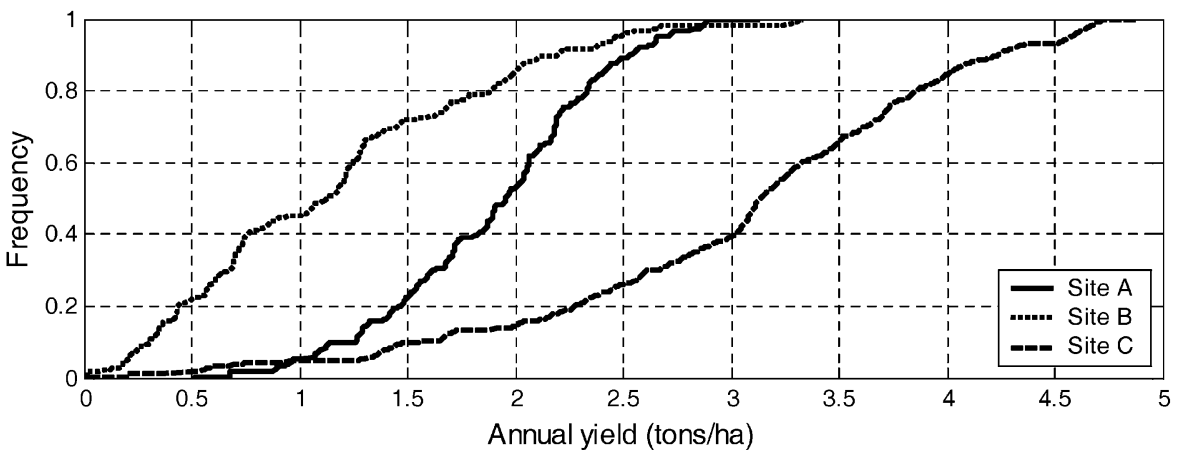

Fig. 8 Cumulative distribution functions $(C D F s)$ at Sites A (solid line), B (dotted line) and C (dashed line). a Annual rainfall. b Yield.

cumulative distribution functions (CDFs) for the three distributions. These curves reveal the proportion of years at each site in which annual rainfall is less than or equal to the values shown on the $x$ axis. For instance, at Site B, about $85 \%$ of the 2,000 years receive $50 \mathrm{~cm}$ of rain or less, whereas no year receives more than $150 \mathrm{~cm}$. At Sites A and C, very few years receive $50 \mathrm{~cm}$ of rain or less, and nearly $30 \%$ receive more than $150 \mathrm{~cm}$.

At each location, we run the model with our simulated monthly rain series until it reaches a statistically steady state, in which there is a stable probability distribution over time of all dynamic variables. We maintain purely seasonal variation in temperature because long time series of temperature for different elevations are lacking. We analyze 2,000 years of steady-state yield, given these climate variables and $85 \%$ harvest, to obtain sample sizes that allow statistically meaningful characterizations of the resulting yearly variation in yield. Yield distributions for Sites A, B, and C appear in Fig. 7 (bottom panel). As in the case of seasonal variation, the effects of stochastic variation differ between sites. As a result, the histograms of annual yield differ substantially from each other and from the corresponding histograms of annual rainfall at the three sites. The CDFs of yield (Fig. 8, bottom panel) emphasize the differences between the rainfall and yield distributions at each site, and express differences between sites in terms of the frequency of yields of given sizes. Closer examination of model dynamics allows us to interpret these patterns in terms of the relationship between stochastic rainfall and agricultural risk.

For each of the three sites, Fig. 9 shows rainfall and realized cropped plant production during four consecutive years chosen at random from the 2,000 years of steady-state yield. 
Due to temperature limitation during the cooler season, sweet potato production at Site A (Fig. 9, top panel) is insensitive to variation in rainfall at those times. During the more productive warmer season, however, fluctuations in plant growth generally coincide with or lag 1 month behind fluctuations in rainfall. This shows that the amount of warm-season rain in a given year is a direct determinant of annual yield (where fluctuations in production coincide with fluctuations in rainfall) and is also an important indirect driver that operates through $\mathrm{N}$ availability (where fluctuations in production lag behind fluctuations in rainfall). Indeed, analysis of decomposition rates shows that stochastic variation in rainfall introduces nonlinear dynamics to this site. Thus, stochastic climatic variation may cause periods of intense competition for $\mathrm{N}$ (via months of higher rainfall during the warm season, for instance). The average yield at Site A is 1.89 tons/ha, with standard deviation $=0.50$ and $\mathrm{CV}=0.26$. The overall effect of plant-soil dynamics is to suppress variability in rain: the ratio of the $\mathrm{CV}$ of yield to the $\mathrm{CV}$ of rain is 0.76 . Still, stochastic variation in rainfall is enough to depress average yield, which was 2.01 tons/ha under seasonal variation. Yield in $26 \%$ of years is 1.5 tons/ha or less, with a minimum of 0.65 tons/ha, while $42 \%$ yield more than 2 tons/ha, with a maximum of 3.09 tons/ha. This analysis shows that farming this site involves some risk of low yields. Prolonged shortage, however, is unlikely. The correlation
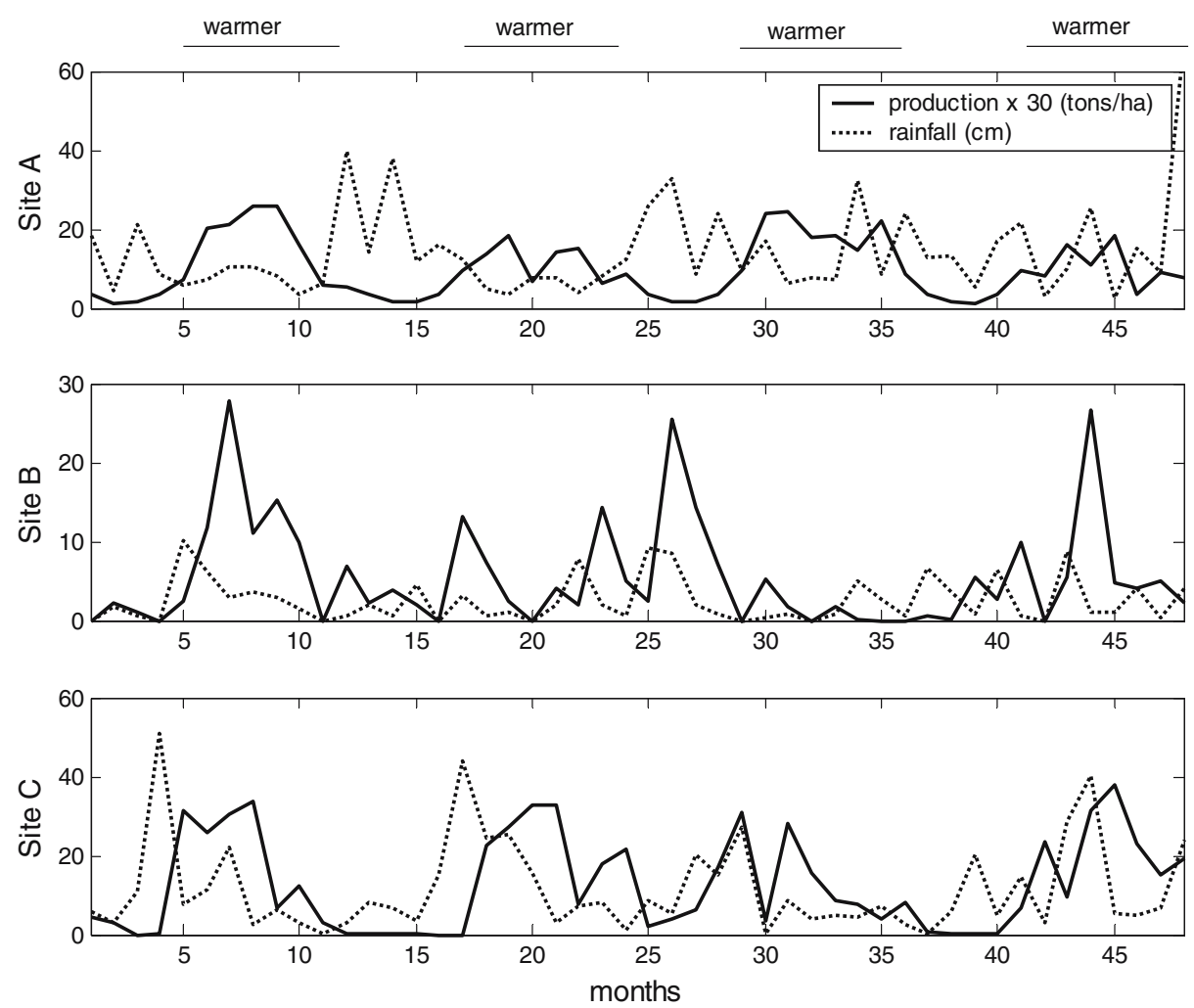

Fig. 9 Time series showing four years of realized plant production in units of tons per hectare $\times 30$ (solid line) and rainfall in units of centimeter (dotted line) at Sites A (top), B (center) and C (bottom). Warmer, drier seasons are indicated at the top of the figure. Note changes in $y$-axes. 
in yield between successive years at Site A is 0.2 . Fitting an exponential decrease to the yield autocorrelation function indicates a "memory" for the correlation of about 7 months, which implies that yields are essentially independent after that time. The characteristic time of the correlation in annual rain is about 10 months, showing that the plant-soil system dynamics are less similar over time than annual rainfall at this site.

At Site B, peaks in growth generally coincide with or lag behind peaks in rain at all times of the year, but the size of the production peaks is highly variable (Fig. 9, center panel). The stochastic variation in rain reintroduces $\mathrm{N}$ limitation to decomposition under cropping, giving rise to nonlinear dynamics in yield. The overall result is high yield variability in both absolute and relative terms: the average yield is 1.15 tons/ha (vs. 1.24 tons/ha in the purely seasonal case) with a standard deviation of 0.71 tons/ha and a CV of 0.62 . The dynamics at this site amplify the variation in rainfall $(\mathrm{CV}$ ratio $=1.29)$. Fully $74 \%$ of years yield 1.5 tons/ha or less, with nearly complete crop failure $(0.005$ tons/ha) in the worst years; downside risk is clearly substantial at this dry and N-poor site. On the other hand, $11 \%$ of years produce more than 2 tons/ha, with a maximum of 3.33 tons/ha. If agriculturalists could make effective use of these rare high payoffs, they could perhaps tolerate the high frequency of low yields. Productivity at this site, however, is unpredictable. Though the correlation in annual rain in successive years is 0.28 , with a memory of about 15 months, the correlation between yields in successive years is about 0.1 , with a characteristic time of only about 5 months. Thus, small yields in a given year do not preclude the possibility of relative bonanza in the next, and vice versa.

Production dynamics at Site C (Fig. 9, bottom panel) differ from those at Site A, again because of the difference in temperature between the two locations. Instead of regular dips in production during the cooler season, we observe occasional periods of very low growth that last variable amounts of time. These periods, which tend to begin during the warmer season, are one of the signs of $\mathrm{N}$ limitation to decomposition: plant growth shuts down for several months while accumulated litter decomposes and consumes N. Thus, intense competition for $\mathrm{N}$ between plants and microbes, and the abrupt, sometimes lengthy failures in plant production caused by the resulting nonlinearities, are important contributors to overall variation. The average yield is 3.03 tons/ha, with a standard deviation of 1.00 tons/ ha and $\mathrm{CV}$ of 0.33 (CV ratio of yield to rain $=0.97$ ). The probability of a low yield is 0.10 , and of a high yield is 0.83 ; the minimum is 0.024 and the maximum 4.95. Although the correlation between levels of precipitation in successive years is 0.28 , so that rainfall memory lasts about 10 months, the correlation between successive yields is -0.05 , which implies a yield memory of less than 1 month. The extreme variability at Site $\mathrm{C}$ thus involves much less continuity in yields through time than would be expected from the dynamics of rainfall.

This detailed analysis shows how temporal variability in rainfall differs from site to site, and demonstrates that the effects of variability on yield also differ depending on average levels of rainfall, temperature, and the strength of nonlinearities that arise from competition between microbes and plants for $\mathrm{N}$. We explore below how the spatial distribution of these factors shapes agricultural risk across rain-fed dryland landscapes.

\section{Describing Variation}

This model generates statistical information on the temporal and spatial variability of annual yield, but it is not obvious how to interpret the level of variation from the perspective of the agriculturalists. Given our goal of linking food supply to population 
dynamics, we now consider a simple model relating yield to population growth. Studies of agricultural populations show that both fertility and mortality vary in response to per capita food supply (e.g., Lee, 1981). Our model describes yield per unit area $Y_{t}$ as a function of time $t$, so we may assume that population vital rates are functions of this yield. The simplest model is to take per capita growth rate $R_{t}$ in a given year to be a linear function of food supply, so that $R_{t}=k Y_{t}$, for some constant $k$. This assumption is consistent with models based on the relationship between nutritional intake and vital rates (Fearnside, 1986). With this assumption, the annual growth rate is a random variable whose statistical distribution is given by the yield distribution generated by our ecological model, and we can calculate the long-term stochastic growth rate that would obtain at each site.

These assumptions lead us to a simple equation for population change: $N_{t+1}=k Y_{t} N_{t}$, where $N_{t}$ is population size at time $t$. The growth rate of such a population over a long period of $t$ years is $r_{S}=\left[\log \left(N_{t}\right)-\log \left(N_{0}\right)\right] / t=E\left[\log \left(Y_{t}\right)\right]+\log (k)$, where the symbol $E$ denotes a statistical average. $r_{S}$ is a density-independent long-term growth rate, analogous to the constant low-density growth rate $r$ in the logistic equation for population growth. Over 2,000 years, the mean of $\log \left(Y_{t}\right)$ is $0.60,-0.14$, and 1.02 at Sites $\mathrm{A}, \mathrm{B}$, and $\mathrm{C}$, respectively. If we assume for the sake of argument that the long-term population growth rate at Site $\mathrm{A}$ is 0.005 , which is a reasonable estimate for precontact Hawaiian populations (Tuljapurkar et al., in press), then $k$ is about 0.55 and $r_{S}$ is -0.74 and 0.422 at Sites B and $\mathrm{C}$, respectively. The corresponding average yearly population growth rate $R_{S}=\exp \left\{r_{S}\right\}$, which is the constant yearly growth rate for the model $N_{t+1}=R_{S} N_{t}$ that gives the same rate of increase over $t$ years as the sequence of varying yearly growth rates $R_{t}$, is $1.005,0.48$, and 1.52 at Sites A, B, and C, respectively. Thus, if agricultural production at Site A could have supported long-term population growth at reasonable rates, Site B would have been inadequate without strategies for increasing yields or reducing their extreme variability. Site $\mathrm{C}$, despite its variability, would have had high enough yields to have supported much higher rates of growth, subsidized populations in other areas, or produced surpluses that could have been important economically, socially and politically. We return to the possibility of sharing between locations in the next section.

Because we assume that yearly growth rates are related to yields by the constant of proportionality $k$, this analysis is very sensitive to the choice of reference site that determines the value of $k$. For instance, we could assume that Site C, rather than Site A, supported population growth at the long-term rate $r_{S}=0.005$. This rate is the estimated growth rate for the entire Hawaiian Archipelago (Tuljapurkar et al., in press), and depended upon yields from irrigated wetland agriculture as well as from dryland farming. To assume that a productive dryland site such as Site $\mathrm{C}$ matched this growth rate is not unreasonable. With this assumption, we find that $k=0.36$, and $r_{S}$ for Sites A and B is -0.42 and -1.16 , respectively $\left(R_{S}=0.66\right.$ for Site $\mathrm{A}, 0.32$ for Site $\left.\mathrm{B}\right)$. Thus, the method yields a useful index of the relative population value of different locations, taking into account variability in food supply, but it does so under specific hypotheses of long-term growth rates at chosen sites.

This simple model cannot provide detailed descriptions of resource use or human population growth in dryland systems. The growth trajectory of human populations may depend on complex social choices, the demographic structure of the population, the availability of able-bodied labor, or other factors. For instance, in any given year, people might use some food to obtain social status or political protection rather than population increase. Moreover, very high yearly or long-term population growth rates are likely beyond human physiological capacity - a doubling in a single year would require every female to bear twins as well as $100 \%$ survival, for example - and hypotheses that produce implausible rates should be interpreted as indicating food surplus even if the population 
were growing maximally. Finally, our model of linear population growth does not take into account density dependence that might occur due to the finite area of the Islands, or of land suitable for agriculture. Modifications to this model that would increase its suitability for human populations, such as the addition of age-specific mortality and fertility rates, of a nonlinear relationship between food and yearly vital rates (which would prevent unrealistically fast growth in any year), or of density dependence, would improve its interpretive power. We are developing more detailed models to make these explicit links between yields and population growth. The basic linear model does, however, capture the qualitative relationship between food and population vital rates, and we present it to suggest the impact that variation in food supply could have in different locations as well as to illustrate the issues involved in relating agricultural yield to human demography. In particular, the argument shows that the average logarithmic yield, $E\left[\log \left(Y_{t}\right)\right]$, or equivalently the geometric average yield, $e^{E[\log (Y t)]}$, is a useful summary measure of the population impact of variability in food supply. In general, if we can describe the yearly growth rate as a function $f\left(Y_{t}\right)$ of annual yield, the relevant quantities are the average of the $\log$ and the geometric mean of $f\left(Y_{t}\right)$. We use $E\left[\log \left(Y_{t}\right)\right]$ and $e^{E[\log (Y t)]}$ in the next section to quantify the effects of yield variation at a landscape level.

\section{Spatiotemporal Variation}

The results above describe how temporal variability in rainfall and yield varies between sites at (or beyond, in the case of Site B) spatial boundaries of the field system. We now extend this analysis to Transects 1 through 4 (Fig. 2) to understand the complete pattern of spatiotemporal variation in food supply within the leeward field system. We generate long stochastic rainfall series at ten evenly spaced points along the field system transects. As before, we simulate monthly temperature at each location using a sinusoid, with annual mean given by elevation. The plant-soil model is then run at each point on each transect to determine the pattern of variation in yields.

Absolute rainfall variation (standard deviation) increases with elevation along all four transects (Fig. 10a), while relative variation (Fig. 10b) increases and then decreases along most transects. Differences between transects in these figures are due to differences in the range of mean rainfall that they span (Fig. 3): more southerly transects (Transects 1, 2) are wetter at their higher ends, as shown in Fig. 3, so that rain $\mathrm{CV}$ begins to decrease for these transects at lower points in Fig. 10b than for more northern ones (Transects 3, 4).

Patterns of yield variation along the four transects do not resemble the patterns of rainfall variation. Unlike rain standard deviation, yield standard deviation (Fig. 10c) decreases with elevation above some point along all transects, though the curve for Transect 4 just levels off at the boundary of the figure. Yield CV (Fig. 10d) decreases monotonically with elevation, also at odds with the rainfall pattern. Figure 10c and d shows that both absolute and relative yield variability are higher along more northern transects than southern ones, so that Transect 4 is most variable at every point and Transect 1 is least variable. Figure 10e shows that the variability along Transect 4 , the northernmost transect, is so great that the relative variation in yield exceeds that in rainfall at all elevations but the highest. Successively more southern transects show systematically decreasing overall variability. Temporal variation in rainfall alone is thus a generally poor indicator of temporal variation in agricultural production.

As at individual sites, the effects of rainfall variability on yield variability depend upon the joint effects of precipitation, temperature, and plant-soil dynamics across the landscape. 
a.

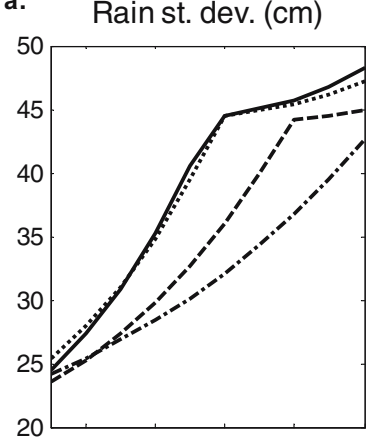

c. Yield st. dev. (tons/ha)

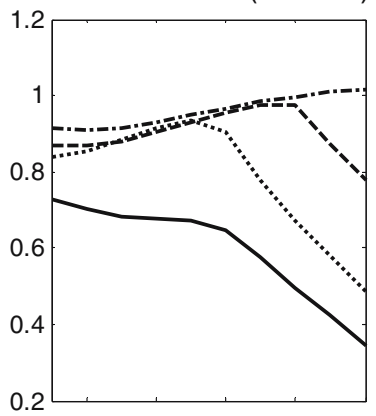

b. Rain CV

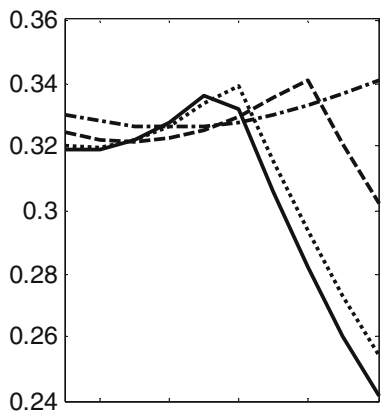

d. $\quad$ Yield CV

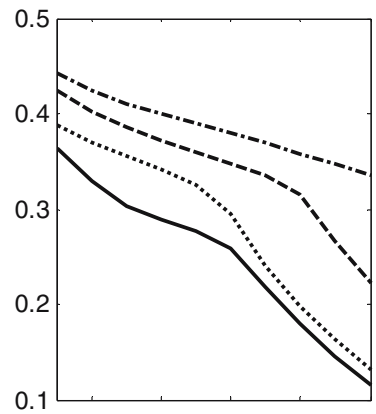

e. Yield CV/RainCV

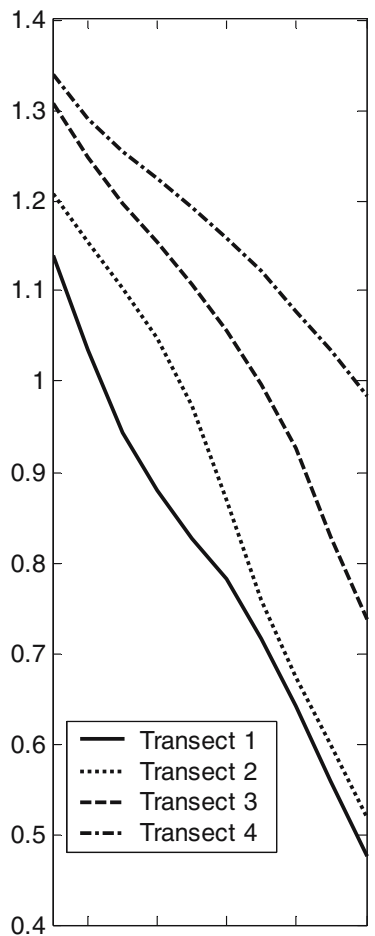

Elevation along each transect

Fig. 10 Measures of rainfall and yield variation along Transects 1 (solid line), 2 (dotted line), 3 (dashed line) and 4 (dash-dot line). Elevation increases from left to right along each transect; $x$-axes show ten evenly spaced points within the field system boundaries along each transect. a Rainfall standard deviation. b Rainfall coefficient of variation (CV). c Yield standard deviation. d Yield CV. e Amplification factor, the ratio of yield $\mathrm{CV}$ to rain $\mathrm{CV}$.

Along each transect, yield fluctuations are greater at lower elevations, where overall levels of rain and $\mathrm{N}$ availability decrease and where temperatures and variability in rainfall increase. Between transects, yields are more variable in the north, where rainfall is similar to the lower portions of more southern transects and where temperatures are higher on average due to decreasing overall elevation (Fig. 3). Warmer temperatures are key because they accelerate potential litter decay, which, in unfertilized dryland agricultural systems based upon starchy crops like sweet potato, increases the likelihood of $\mathrm{N}$ limitation to decomposition. This process sometimes shuts down plant growth for extended periods, introducing increasing nonlinear variation to lower elevations along transects and to northern transects.

Figure 11a shows mean yields along each of the four transects. In all cases, mean annual yield increases with elevation due to a combination of increased rainfall, increased $\mathrm{N}$ input, and decreased variability. Thus, along each transect, these benefits of increasing elevation outweigh decreases in potential production due to decreasing temperatures, though the net benefit is less along the higher-elevation southern transects. Higher temperatures farther north in the field system explain why Transect 2 is higher yielding than Transect 1, but Transects 3 and 4 yield successively less than Transect 2 on average. This effect is due to 
a.

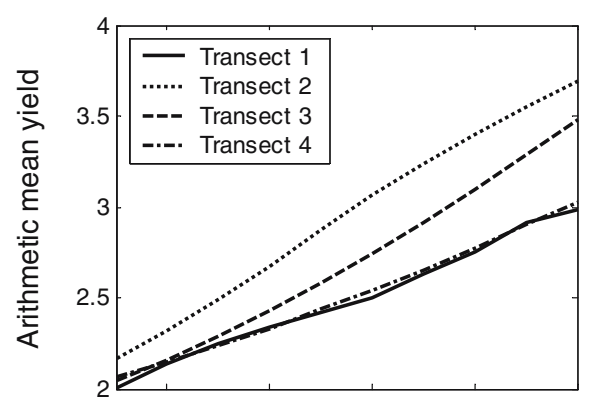

c.

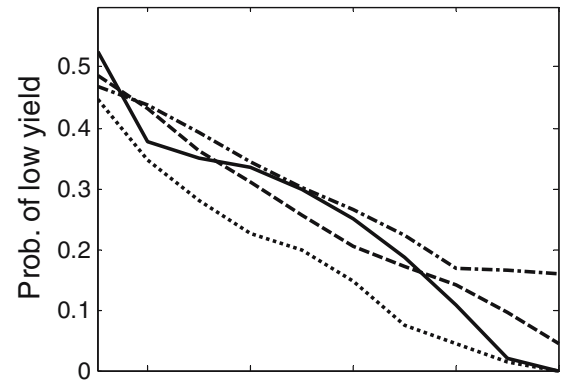

b.

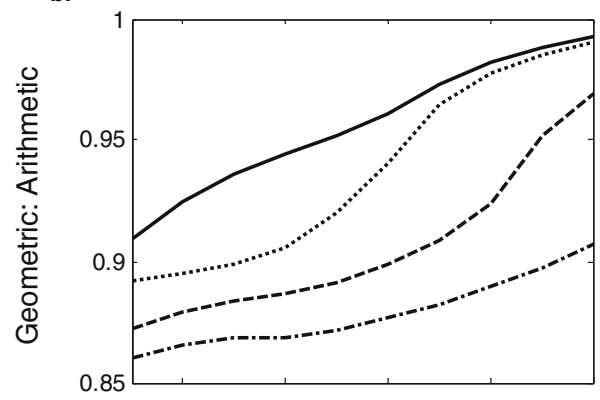

d.

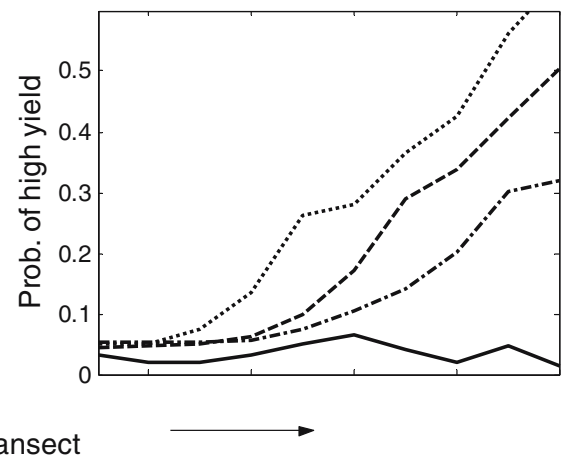

Fig. 11 a Mean yields. b Ratio of the geometric mean to the arithmetic mean, showing the extent to which arithmetic means fail to account for yield variability. c Probabilities of yields less than or equal to 2 tons/ ha. d Probabilities of yields greater than 3.5 tons/ha. Solid line: Transect 2. Dotted: Transect 4. Dashed: 5. Dash-dot: 6.

the increasing temporal variation in northern areas. As we saw earlier, the geometric mean yield is a more useful quantity for assessing the population impacts of temporal variation than is the arithmetic mean yield. Figure $11 \mathrm{~b}$ shows the ratio of the geometric mean, $e^{E[\log (Y t)]}$, to the arithmetic mean, $E\left[Y_{t}\right]$. This ratio illustrates the extent to which arithmetic mean yields overestimate the agricultural value of each site due to their failure to account for temporal variation, and shows that the impact of variation increases from south to north. Figure 11c and $\mathrm{d}$ compares the transects in terms of their probabilities of yielding 2 tons/ha or less and greater than 3.5 tons/ha. All four transects show probabilities of a low yield (Fig. 11c) that decline with elevation, and Transect 2 has fewer low-yielding years at each elevation than the other three transects. Figure 11d shows that Transect 1 has a low probability of high yields along its entire length. The other three transects show dramatic increases in the frequency of large yields with elevation, with Transect 2 showing the largest overall effect. Transects 3 and 4 have substantial probabilities of high yields at higher elevations, emphasizing that their high variability could have provided benefits if methods had been devised to mitigate bad years or exploit good ones.

What effect would sharing along elevational transects have on the temporal dynamics of yield? The Hawaiian land tenure system was based on ahupua'a, which were generally strips of land running from a mountain ridge to the coast (Ladefoged and Graves, 2006). 
Communities of commoners lived on the land and farmed it, but its administration was in the hands of a hierarchy of social elites. Though this organization may have originated to provide access to agricultural, forest, and fishing resources to each community, it may also have evolved dynamically for reasons relating to productivity (Ladefoged and Graves, 2006). Analyzing yields that are pooled along elevational transects casts light on one likely way in which Hawaiians managed their agricultural resources. Table II contains the means, standard deviations, and CVs of yields averaged along the four transects. Mean yields are similar between Transects 1 and 4, and Transects 2 and 3 show highest averaged yields. Averaging along transects mitigates the yield CVs at the extremes of each, with each wholetransect CV lying between the high value of the dry end and the low value of the wet end. Averaging does not reduce the overall differences in $\mathrm{CV}$ between transects, however: the northern transects still show substantial temporal variability in yield. This occurs because yields along northern transects are much more highly correlated with each other than in the south, so that above average yields at some elevations generally do not mitigate below average yields elsewhere along northern transects (Table II). Sharing along these northern transects thus does not reduce temporal variation in yield as much as would be expected if spatial correlations were lower. It is, however, clearly a better way of managing agricultural risk within the field system than, say, sharing along elevational contours, which would have exposed the lowest yielding and most variable communities at the bottom edge of the field system to considerable fluctuations in food supply.

Table II shows that the northernmost Transect 4 has the highest probability of low yield of the four, coupled with a probability of high yield that is better only than that at Transect 1. Transect 2 stands out as having the lowest probability of bad yields and highest probability of good yields. The mean of the $\log \left(Y_{t}\right)$ at Transects $4,3,2$, and 1 is $0.80,0.92$, 1.04 , and 0.89 , respectively (Table II). If we assume that the long-run growth rate of a population surviving only on yields from Transect 3 is 0.005 , then $k=0.40$ and the longterm population growth rates $r_{s}$ at Transects 4,2 , and 1 are $-0.11,0.13$, and -0.03 for comparison. The corresponding average yearly growth rates $R_{s}$ are $0.90,1.005,1.14$, and 0.97 , respectively, from north to south. If instead we use Transect 2 as the reference, then $k=$ $0.36, r_{s}$ is $-0.24,-0.12$, and -0.14 at Transects 4,3 , and 1 , respectively, and $R_{s}$ is 0.79 , 0.89 , and 0.86 . We can use each of these two values of $k$ to calculate the values of $R_{s}$ that each site would achieve if no sharing occurred (Fig. 12). The choice of reference transect influences the numerical values of the population-value index, but regardless of this choice, 1) Transect 2 is the most valuable by far; 2) Transect 1 emerges as more valuable than Transect 4 due to its greater stability; and 3) substantial surpluses at higher-elevation locations are necessary to subsidize less productive, more variable lower-elevation sites to

Table II Yield Statistics for Transects 4, 3, 2, and 1 in the Kohala Field System (see Fig. 2) Assuming Sharing Along each Transect

\begin{tabular}{llllllll}
\hline Transect & $\begin{array}{l}\text { Mean of } \\
\text { averaged } \\
\text { yield } \\
\text { (tons/ha) }\end{array}$ & $\begin{array}{l}\text { Standard } \\
\text { deviation } \\
\text { of averaged } \\
\text { yield }\end{array}$ & $\begin{array}{l}\text { CV of } \\
\text { averaged } \\
\text { yield }\end{array}$ & $\begin{array}{l}\text { Correlation } \\
\text { between } \\
\text { boundaries }\end{array}$ & $\begin{array}{l}\text { Frequency of } \\
\text { averaged yield } \\
<=2 \text { tons/ha }\end{array}$ & $\begin{array}{l}\text { Frequency of } \\
\text { averaged yield } \\
>3.5 \text { tons/ha }\end{array}$ & $E\left[\log \left(Y_{t}\right)\right]$ \\
\hline 4 & 3.01 & 0.93 & 0.37 & 0.75 & 0.27 & 0.09 & 0.80 \\
3 & 3.24 & 0.86 & 0.32 & 0.60 & 0.22 & 0.13 & 0.92 \\
2 & 3.54 & 0.72 & 0.24 & 0.36 & 0.12 & 0.18 & 1.04 \\
1 & 2.99 & 0.54 & 0.22 & 0.38 & 0.22 & 0.02 & 0.89 \\
\hline
\end{tabular}

Ten elevations are modeled on each transect. 

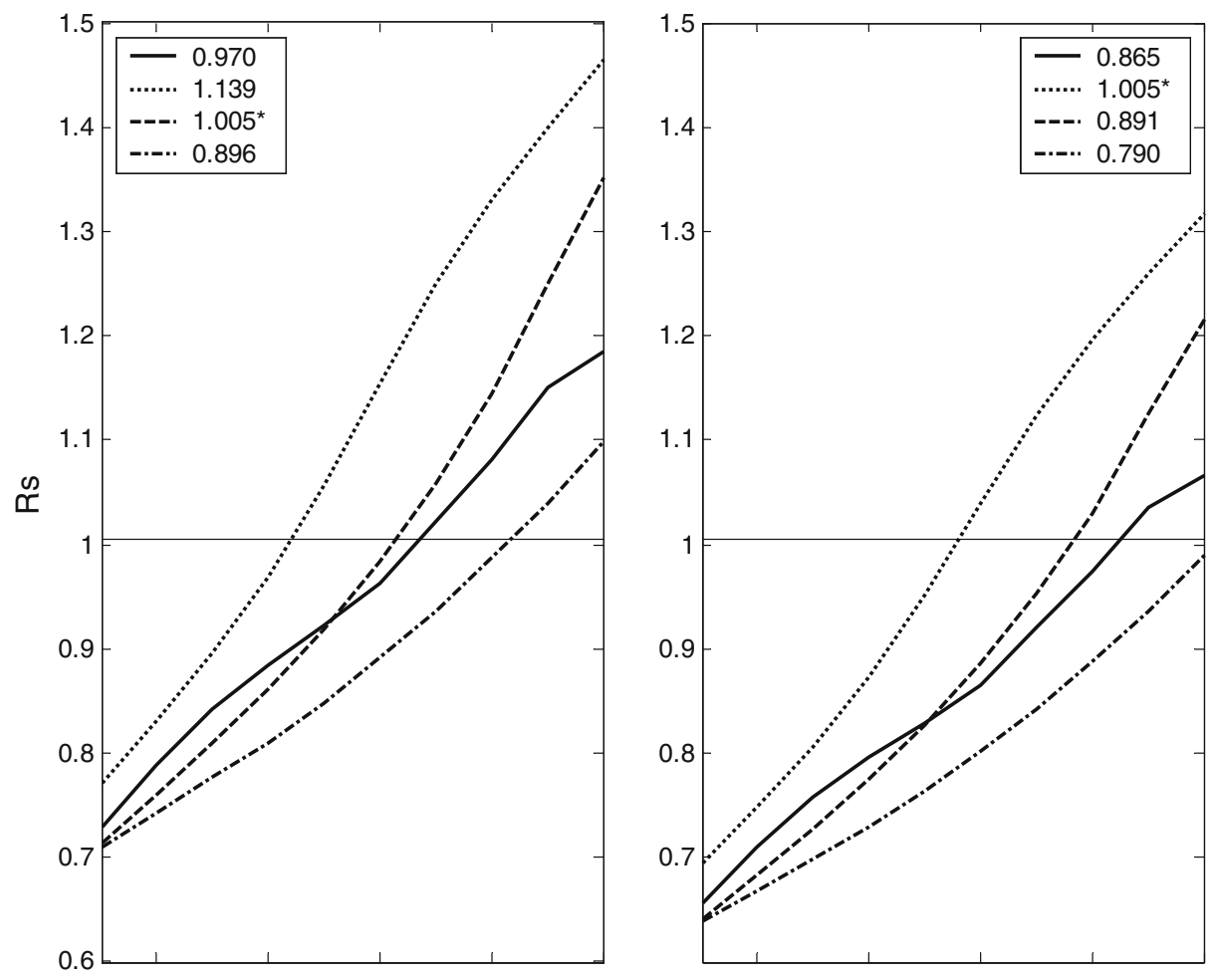

\section{elevation along each transect}

Fig. 12 Long-run growth rates $R_{S}$ that could be achieved in isolation, under the hypothesis that yields are shared along transects (see text for details). Left panel: Growth rate of Transect 3 (dashed lines), given sharing, is assumed to be 1.005. Right panel: Growth rate of Transect 2 (dotted lines) is assumed to be 1.005 . Solid lines: Transect 1. Dash-dot lines: Transect 4.

achieve even modest whole-transect growth rates. Ahupua'a near Transect 2 and locations near the upper boundary of the field system would have had the highest population growth rates, or the greatest agricultural surpluses per unit labor, or some combination of benefits. Transects further north are increasingly less profitable because of their variability, while those to the south suffer from increasing elevations and lower average temperatures that suppress sweet potato growth.

\section{Discussion}

When used to explore yield dynamics over an entire dryland field system, our approach demonstrates how the system's limitations and vulnerabilities change over space. Highelevation sites are too cool for robust plant growth, and areas that are too dry lack both moisture and N. Model dynamics also reveal that high variability in yield due to Ndemanding litter decomposition may reduce the utility of warm, moist locations for starch staple production. The interaction between temperature and rainfall dynamics determines 
the temporal pattern of yields at any given site. Though we parameterized our model for the Kohala peninsula, our results rest on general principles that we believe can be expected to hold for dryland agriculture elsewhere, and our approach for producing quantitative estimates of food supply by integrating climate, plants, and soil dynamics is general.

The results we have presented show that yields increase and variability decreases with elevation along every transect. They thus do not reveal any reason not to cultivate higher up the slope, especially along lower-elevation transects where temperature limitation would not be a factor. As we know, however, leaching of base cations and $\mathrm{P}$ causes reductions in these essential rock-derived plant nutrients at high levels of rainfall (Kirch et al., 2004, Vitousek et al., 2004). These previous studies show that above a threshold level of rainfall $\mathrm{P}$ limitation that is not captured by our model depresses yields and defines the upper boundary of the field system. We can relate our work to these studies by using our model to predict $\mathrm{P}$ harvest losses within the field system, using the assumption that $\mathrm{P}$ is not limiting below its upper boundary. Table III shows the calculated mean P harvest flux at the bottom and top boundaries of the field system. To integrate such predicted harvest losses of $\mathrm{P}$ with expected leaching losses and to compare the results with current observed patterns of $\mathrm{P}$ abundance across the field system (Vitousek et al., 2004) is an important direction for future research.

Human choices could change our picture of temporal and spatial variability substantially. Humans might have been able to reduce their vulnerability to yield fluctuation, or even to reduce the fluctuation itself. $\mathrm{N}$ availability, for instance, is a crucial component of the nonlinear dynamics described above. If $\mathrm{N}$ were abundant enough to supply both decomposition and plant growth at all times, yield variability would be much reduced. Preindustrial agriculturalists might have increased soil $\mathrm{N}$ by harvesting a smaller percentage of root tissue or by allowing fallow periods (both of which, however, would also have reduced yields), by mulching with plant material from outside the field system, or by effectively fertilizing with $\mathrm{N}$-fixing plants grown within the system. $\mathrm{N}$ additions would also increase yields. Alternatively, storage or sharing mechanisms could mitigate the impact of yield fluctuations on human populations. Aside from storing sweet potatoes themselves, agriculturalists might have practiced other forms of effective storage, such as feeding tubers to animals such as pigs. Planting different crops in different areas - planting dryland taro in areas that are too cool for sweet potato, for instance-could also mitigate variability. Finally, more extensive sharing across space, such as between ahupua'a in a district or between wetland and dryland agricultural regions, could affect the variation in food supply at different locations. Future modeling work should assess the potential impact of many of these strategies. Our improved understanding of temporal and spatial variation in dryland yields and, more importantly, the potential sources of variability, brings clearer focus to these important questions about the societal value of dryland agriculture, and provides a biological basis for a quantitative understanding of carrying capacity in marginal agricultural regions.

Table III Predicted Flux of Phosphorus (P) out of Soil Due to Sustainable Harvest at the Endpoints of each Transect (see text for details)

\begin{tabular}{lll}
\hline Transect & $\begin{array}{l}\text { Mean P flux at lower } \\
\text { boundary }\left(\mathrm{g} / \mathrm{m}^{2} / \text { year }\right)\end{array}$ & $\begin{array}{l}\text { Mean P flux at upper } \\
\text { boundary }\left(\mathrm{g} / \mathrm{m}^{2} / \text { year }\right)\end{array}$ \\
\hline 4 & 0.106 & 0.156 \\
3 & 0.105 & 0.179 \\
2 & 0.111 & 0.190 \\
1 & 0.103 & 0.154 \\
\hline
\end{tabular}


Acknowledgments This research was supported by National Science Foundation (NSF) Grant BCS0119819. We are grateful to M. Richards, Kahua Ranch, and O. Chadwick for providing rainfall data, and to C. Puleston for valuable assistance with climate modeling. We also thank O. Chadwick for indispensable advice regarding soils, and W. Parton for the same regarding CENTURY. We thank A. Hartshorn, P. Kirch, T. Ladefoged, C. Puleston, and two anonymous reviewers for helpful comments on previous versions of the manuscript.

\section{References}

Allen, M. S. (2004). Bet-hedging Strategies, Agricultural Change, and Unpredictable Environments: Historical Development of Dryland Agriculture in Kona, Hawaii. Journal of Anthropological Archaeology 23: 196-224.

Baisden, W. T., and Amundson, R. (2003). An Analytical Approach to Ecosystem Biogeochemistry Modeling. Ecological Applications 13: 649-663.

Bolker, B. M., Pacala, S. W., and Parton, W. J. (1998). Linear Analysis of Soil Decomposition: Insights from the Century Model. Ecological Applications 8: 425-439.

Burke, I. C., Lauenroth, W. K., and Parton, W. J. (1997). Regional and Temporal Variation in Net Primary Production and Nitrogen Mineralization in Grasslands. Ecology 78: 1330-1340.

Burtenshaw, M., Harris, G., Davidson, J., and Leach, F. (2003). Experimental Growing of Pre-European Cultivars of Kumara (Sweet Potato, Ipomoea batatas [L.] Lam.) at the Southern Margins of Maori Horticulture. New Zealand Journal of Archaeology 23: 161-188.

Chadwick, O. A., Derry, L. A., Vitousek, P. M., Huebert, B. J., and Hedin, L. O. (1999). Changing Sources of Nutrients During Four Million Years of Ecosystem Development. Nature 397: 491-497.

Chadwick, O. A., Gavenda, R. T., Kelly, E. F., Ziegler, K., Olson, C. G., Elliott, W. C., and Hendricks, D. M. (2003). The Impact of Climate on the Biogeochemical Functioning of Volcanic Soils. Chemical Geology 202: $195-223$.

Comins, H. N., and McMurtrie, R. E. (1993). Long-Term Response of Nutrient-Limited Forests to Co2 Enrichment-Equilibrium Behavior of Plant-Soil Models. Ecological Applications 3: 666-681.

Fearnside, P. M. (1986). Human Carrying Capacity of the Brazilian Rainforest. Columbia University Press, New York.

Giambelluca, T. W., and T. A. Schroeder. (1998). Climate. In Juvik, S. P., and Juvik, J. O. (eds.), Atlas of Hawai'i. University of Hawai'i, Honolulu, pp. 49-59.

Kirch, P. V. (1985). Feathered Gods and Fishhooks. University of Hawaii, Honolulu.

Kirch, P. V. (1994). The Wet and the Dry: Irrigation and Agricultural Intensification in Polynesia. University of Chicago, Chicago.

Kirch, P. V., Chadwick, O. A., Tuljapurkar, S., Ladefoged, T. N., Graves, M. W., Hotchkiss, S. C. and Vitousek, P. M. (in press). Human ecodynamics in the Hawaiian ecosystem, 1200-200 BP. In Kohler, T. (ed.), Modeling Long-Term Culture Change. Oxford University Press (for Santa Fe Institute).

Kirch, P. V., Hartshorn, A. S., Chadwick, O. A., Vitousek, P. M., Sherrod, D. R., Coil, J., Holm, L., and Sharp, W. D. (2004). Environment, Agriculture, and Settlement Patterns in a Marginal Polynesian Landscape. Proceedings of the National Academy of Sciences of the United States of America 101: 9936-9941.

Ladefoged, T. N., and Graves, M. W. (2000). Evolutionary Theory and the Historical Development of DryLand Agriculture in North Kohala, Hawai'i. American Antiquity 65: 423-448.

Ladefoged, T. N., and Graves, M. W. (2006). The formation of Hawaiian territories. In Lilly, I. (ed.), Archaeology of Oceania. Blackwell Press, New York, pp. 259-283.

Ladefoged, T. N., Graves, M.W. and McCoy, M. (2003). Archaeological evidence for agricultural development in Kohala, Island of Hawai'i. Journal of Archaeological Science 30: 923-940.

Lee, R. (1981). Short-term variation: vital rates, prices, and weather. In Wrigley, E. A., and Schofield, R. S. (eds.), The Population History of England: A Reconstruction, Edward Arnold, London, pp. 541-1871.

Linacre, E. T. (1977). A Simple Formula for Estimating Evaporation Rates in Various Climates, Using Temperature Data Alone. Agricultural Meteorology 18: 409-424.

Metherell, A. K., Harding, L. A., Cole, C. V., and Parton, W. J. (1993). CENTURY soil organic matter model environment. Technical Documentation Agroecosystem Version 4.0. Technical Report No. 4, Great Plains Systems Research Unit, USDA-ARS, Fort Collins, Colorado.

Onwueme, I. C. (1978). The tropical Tuber Crops: Yams, Cassava, Sweet Potato, and Cocoyam. Wiley, New York. 
Parton, W. J., Schimel, D. S., Cole, C. V., and Ojima, D. S. (1987). Analysis of Factors Controlling Soil Organic-Matter Levels in Great-Plains Grasslands. Soil Science Society of America Journal 51: 11731179 .

Parton, W. J., Neff, J., and Vitousek, P. M. (2005). Modelling Phosphorus, Carbon, and Nitrogen Dynamics in Terrestrial Ecosystems. Organic P Symposium.

Purseglove, J. W. (1968). Tropical Drops: Dicotyledons. Wiley, New York.

Raich, J. W., Parton, W. J., Russell, A. E., Sanford, R. L., and Vitousek, P. M. (2000). Analysis of Factors Regulating Ecosystem Development on Mauna Loa Using the Century Model. Biogeochemistry 51: 161-191.

Tuljapurkar, S., Lee, C. T., and Figgs, M. (in press). Demography and food in early Polynesia. In Kirch, P. V., and Rallu, J.-L. (eds.), He Growth, Regulation, and Collapse of Island Societies: Archaeological and Demographic Perspectives from the Pacific. University of Hawai'i, Honolulu.

Vitousek, P. M. (2004). Nutrient Cycling and Limitation: Hawai'i as a Model System. Princeton University Press, Princeton, New Jersey.

Vitousek, P. M., Ladefoged, T. N., Kirch, P. V., Hartshorn, A. S., Graves, M. W., Hotchkiss, S. C., Tuljapurkar, S., and Chadwick, O. A. (2004). Soils, Agriculture, and Society in Precontact Hawai. Science 304: 1665-1669.

Woolfe, J. A. (1992). Sweet Potato: An Untapped Food Resource. Cambridge University Press, Cambridge.

Yen, D. E. (1974). The Sweet Potato and Oceania: an Essay in Ethnobotany. Bishop Museum, Honolulu, Hawaii. 